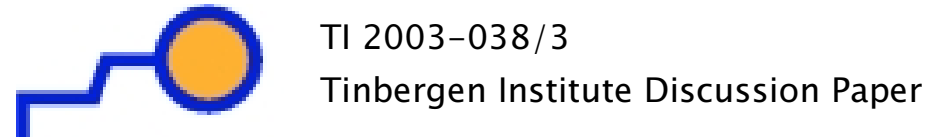 Strategic Interactions of Bilateral Monopoly on a Private Highway
}

\author{
Judith Y.T. Wang \\ Hai Yang ${ }^{\prime}$ \\ Erik T. Verhoef
}

' Dept of Civil Engineering, The Hong Kong University of Science and Technology, Hong Kong, 2 Dept of Spatial Economics, Faculty of Economics and Business Administration, Vrije Universiteit Amsterdam, and Tinbergen Institute. 


\section{Tinbergen Institute}

The Tinbergen Institute is the institute for economic research of the Erasmus Universiteit Rotterdam, Universiteit van Amsterdam, and Vrije Universiteit Amsterdam.

Tinbergen Institute Amsterdam

Roetersstraat 31

1018 WB Amsterdam

The Netherlands

Tel.: $\quad+31(0) 205513500$

Fax: $\quad+31(0) 205513555$

Tinbergen Institute Rotterdam

Burg. Oudlaan 50

3062 PA Rotterdam

The Netherlands

Tel.: $\quad+31(0) 104088900$

Fax: $\quad+31(0) 104089031$

Please send questions and/or remarks of nonscientific nature to driessen@tinbergen.nl.

Most TI discussion papers can be downloaded at http://www.tinbergen.nl. 


\title{
Strategic Interactions of Bilateral Monopoly on a Private Highway
}

\author{
Judith Y T Wang and Hai Yang \\ Department of Civil Engineering, The Hong Kong University of Science and Technology, \\ Clear Water Bay, Kowloon, Hong Kong, P.R. China \\ and \\ Erik T Verhoef \\ Department of Spatial Economics, Free University Amsterdem \\ De Boelelaan 1105, 1081 HV Amsterdam, The Netherlands
}

\begin{abstract}
This paper investigates strategic interactions between a private highway operator and a private transit operator who uses the same highway for its services. Heterogeneity of travellers is taken into account by considering a continuous distribution of values of time. Demand elasticity arises from the inclusion of an outside virtual mode. Game theory is applied to model the possible moves taken by the operators in their interactions. Four games are formulated, representing different decision making processes, including Nash and Stackelberg (leader-follower) games. The different timings of long-run and short-run decisions are also modeled in a two-stage game. Our results indicate that the market equilibria in the four games formulated are quite different as a result of the different sequences of moves. The highway operator is considered to be in a better position in terms of profit making in most cases, while for the transit operator it will generally be more advantageous to be the follower rather than in the leader position.
\end{abstract}

Keywords: Bilateral monopoly; private highway; private bus services; game theory; competitive equilibrium

\section{Introduction}

The private provision of both highway infrastructure and transportation services has grown rapidly worldwide. For example, in mainland China, many intercity highways such as the Guangzhou-Shenzhen super-highway, the Jiangsu expressway and the Zhejiang expressway are provided commercially and privately through so-called Build-Operate-Transfer (BOT) schemes. Furthermore, on the private highways, private bus firms offer competitive bus services to travellers for profit-making purposes. Such commercial and private provision of both highway infrastructure and transport services has attracted fast-growing interest recently, and is increasingly being used or at least considered to finance modern transportation systems. In Hong Kong, private sector participation in both transportation infrastructure and services has worked well in a number of projects, such as road tunnels and bus services. 
A unique situation will arise on a private highway when the use of the highway is not only for private vehicles, but also for a transit service. A hierarchical, bilateral two-level monopoly then arises, the first level being the highway operator and the second the transit operator. The relationship between the two parties is unique in the sense that the transit operator is a customer of the highway operator as well as a competitor. A third group involved will be the travellers, who face the decision of which mode to take so as to make their journeys at minimum costs. While the highway operator tries to maximise profit by optimising the tolls for private and transit vehicles, the transit operator also optimises the service frequency and fare in order to maximise profit. The highway operator's decision on the tolls for private and transit vehicles will directly affect the transit operator's market share and marginal profit conditions. On the other hand, the transit operator's decision on the frequency and fare will in turn affect the highway operator's profit, as the service quality in terms of frequency will directly affect the number of private vehicle users. Their decisions together will affect the travellers' decisions, in turn affecting the operators' resulting market shares and profits. The two operators' profits are thus interrelated, and when making their supply and pricing decisions, they will naturally consider each others' and the travellers' (mode choice) responses.

Questions that then arise include the following: Will there be any market equilibria between the two operators, and would the equilibrium depend strongly on the type of interaction - or: the details of the game played - between the two operators? What will be the implications for social welfare? If government's regulation is required, how should this be designed, and what would be the socially optimum tolls, fare and service frequency? Else and James (1995) investigated the effect of bilateral monopoly and complementary monopoly in rail services on the service price and quality. Their results indicated a general fall in the output and quality of train service, and hence poor welfare outcomes. What will be the case on a private highway? Pedersen (1998) modelled the strategic interactions in a transport market as a differentiated duopoly. Pedersen (1998) found that in case of substitute services, the companies' actions being strategic complements (like prices in Bertrand competition with differentiated products) will result in a second mover advantage, while strategic substitutes (like capacities or outputs in Cournot competition) will result in a first mover advantage. In contrast, in the case of complementary services, the results will be reversed. What will be the case in our bilateral monopoly relationship?

This paper aims to provide insight into these questions by investigating the possible strategic interactions between the highway and transit operators, taking into consideration the travellers' behaviour and demand elasticity. In order to model the interactions between the two operators' and the travellers' decisions, a two-level equilibrium model is formulated. The first level models the market equilibrium between the highway operator and transit operator as a result of their strategic interactions. The second level models the demand equilibrium as a result of the mode choice behaviour of travellers. The case studied, we believe, is relevant 
in its own right given the increasing interest in privatization of roads and of public transport companies. Apart from that, comparable problems may arise in other transportation markets or indeed, network markets more generally - when the infrastructure owner (or a company historically closely related to it) offers services but has to give priced access to competing service providers.

In our demand equilibrium model, travellers' mode choices is assumed to be based on the generalised cost of the journey, which is the sum of the monetary cost and travel time weighted by the value of time (VOT). Travellers are assumed to be heterogeneous in terms of their values of time. In other words, while travellers have the same objective in minimising their generalised cost, their optimal mode choices may be different, depending on their VOT. Differences in VOT may for instance result from differences in income levels, other socioeconomic characteristics, trip purpose, and may furthermore - for an individual - vary from day to day depending on practical circumstances. Dispersion in values of time has received attention before as a factor affecting welfare properties of equilibria in transport markets. Dodgson and Katsoulacos (1988) modelled the quality competition in bus services by considering consumers having identical tastes but different incomes. The demand equilibrium was obtained by partitioning the distribution of income based on the utility values of bus services as a function of the prices. Banks (1991) examined the effect of value-of-time distributions on transit headway optimisation using a binary probit demand model. Recently Verhoef and Small (2000) explored the properties of various types of constrained congestion pricing, with heterogeneous users and allowing for elastic demand. Heterogeneity was modelled by a continuum of VOT and demand elasticity was modelled by assuming an elastic demand function for every value of time. More recently Yang et al (2001) modelled the demand equilibrium in competitive bus services defined as when no user can reduce individual trip cost by unilaterally switching his travel mode. The demand equilibrium was obtained by partitioning the distribution of VOT into market segments corresponding to different quality of services. The same approach is adopted to model the mode choice behaviour in this study. Demand elasticity is here considered by including a virtual mode in the mode choice set (we assume rail), and hence pertains only to individuals who are indifferent between this virtual mode, and the bus service on the road under consideration. This virtual mode might represent the existing travel mode in the do-nothing (i.e. no toll road and hence no bus service on it) case. The fare and frequency of service for this virtual mode are assumed to be exogenous - which is probably an unrealistic assumption, but one that allows us to concentrate on the already complex interactions between the transit and highway operator. In this paper, an existing railway parallel to the private highway is assumed.

The key purpose of this paper is to study the interactions between the operators, and to determine any possible resulting equilibria between them at a strategic level. Game theory is applied to model the interactions between the operators at a strategic level. Simplistic functions are therefore adopted, such that results can be obtained to provide insights into the 
nature of the problem. For manageability of the model, the effect of congestion on the travel time is ignored. Moreover, the bus capacity is assumed to be a constant and exogenous to the decision problem considered. Various competitive games are formulated to represent the different sequences of moves of the two operators in making the supply and price decisions. A two-stage game is also formulated, to model the effect of bus frequency as a longer term decision.

\section{The Model}

We consider a new private highway, connecting a single origin-destination pair, and running parallel with an existing railway line. The capacity of the highway is assumed to be constant. Apart from setting a toll for private vehicles, the highway operator has to decide whether to allow transit service to operate on the highway, and if so, what toll to charge for transit vehicles. The transit operator has to decide whether to provide transit service on the highway and if so, the fare and frequency of service. The bus capacity for transit service is assumed to be constant.

Before going into details of the equilibrium models, the decision variables and model parameters are defined as shown in Table 1. The main notational conventions to be remembered are as follows: $F$. denotes frequencies of buses and flows of cars, while $Q$. denotes patronage for transit; $T_{\bullet}$. denotes travel times; $\tau$ denotes the value of time; $t_{\bullet}$ denotes tolls charged by the highway operator; $f$. denotes fares (for transit) or private costs (for car users), while $f(\tau)$ denotes the density function for $\tau$; $C_{v}$. denotes variable cost parameters and $C_{f}$. fixed costs; $G_{\bullet}$. denotes generalized costs (i.e., for users); $W$ denotes expected waiting times for transit users; modes are distinguished by subscripts $c$ (car) for private vehicles, $b$ (bus) for transit, and $r$ (rail) for the virtual mode; and profits are denoted with $\pi$.

\subsection{Demand equilibrium}

The generalised cost is defined as the time cost (travel time weighted by the specific VOT of the traveller) plus the fare. Assuming travellers' mode choice is based on generalised cost, the optimal choice of a traveller with VOT $(\tau)$ will be the mode associated with the minimum generalised cost $G$ among the three modes, with:

$$
\begin{aligned}
& G_{b}(\tau)=f_{b}+\left(T_{b}+W\left(F_{b}\right)\right) \tau \\
& G_{c}(\tau)=f_{c}+T_{c} \tau+t_{c} \\
& G_{r}(\tau)=f_{r}+T_{r} \tau
\end{aligned}
$$


where

$W\left(F_{b}\right)=\frac{1}{2 F_{b}}$

$W\left(F_{b}\right)$ is the expected waiting time for transit service, assuming that transit users do not have knowledge of the bus timetable. Waiting time for the virtual mode is not considered in the generalised cost function (it is incorporated in the travel time $T_{r}$ or it is assumed that the time schedule is known).

The following relationships between the fares and travel times on the three transport modes are assumed to apply:

$f_{r}<f_{b}<f_{c}+t_{c}$

$T_{c}<T_{b}+W\left(F_{b}\right)<T_{r}$

As a result of the above equations (1)-(6), the market will be partitioned in three segments, where users with a low VOT use the virtual mode, with an intermediate VOT the transit service, and with a high VOT the car. We can easily derive the critical VOT's at which users are indifferent between two modes.

Users with VOT $(\tau)$ such that $G_{c}(\tau)<G_{b}(\tau)$ and $G_{c}(\tau)<G_{r}(\tau)$ will strictly prefer driving than transit services. The implied cut-off VOT $\left(\bar{\tau}_{b c}\right)$ is at:

$G_{b}\left(\bar{\tau}_{b c}\right)=G_{c}\left(\bar{\tau}_{b c}\right)$

$f_{b}+\left(T_{b}+W\left(F_{b}\right)\right) \bar{\tau}_{b c}=f_{c}+T_{c} \bar{\tau}_{b c}+t_{c}$

$\bar{\tau}_{b c}=\left(f_{c}+t_{c}-f_{b}\right)\left(T_{b}+\frac{1}{2 F_{b}}-T_{c}\right)^{-1}$

Users with VOT $(\tau)$ such that $G_{b}(\tau)<G_{c}(\tau)$ and $G_{b}(\tau)<G_{r}(\tau)$ will strictly prefer the new transit service to driving and existing transit service. The lower cut-off VOT $\left(\bar{\tau}_{b r}\right)$ is at:

$$
\begin{aligned}
& G_{b}\left(\bar{\tau}_{b r}\right)=G_{r}\left(\bar{\tau}_{b r}\right) \\
& f_{b}+\left(T_{b}+W\left(F_{b}\right)\right) \bar{\tau}_{b r}=f_{r}+T_{r} \bar{\tau}_{b r}
\end{aligned}
$$


$\bar{\tau}_{b r}=\left(f_{b}-f_{r}\right)\left(T_{r}-T_{b}-\frac{1}{2 F_{b}}\right)^{-1}$

Let $f(\tau)$ be the density function of the distribution of VOTs across the user population. For simplicity, assuming that the distribution is represented by a uniform distribution between an exogenous minimum $\theta_{1}$ and maximum $\theta_{2}$, i.e. $\tau \in\left[\theta_{1}, \theta_{2}\right]$

$f(\tau)=\frac{1}{\theta_{2}-\theta_{1}} \quad$ where $\theta_{1} \leq \tau \leq \theta_{2}$

At demand equilibrium, the market shares of each of the three modes, for a given total number of $Q$ users, are then as follows:

$$
\begin{aligned}
& F_{c}=Q \int_{\bar{\tau}_{b c}}^{\theta_{2}} f(x) d x=Q\left(\frac{\theta_{2}-\bar{\tau}_{b c}}{\theta_{2}-\theta_{1}}\right) \\
& Q_{b}=Q \int_{\bar{\tau}_{b r}}^{\bar{\tau}_{b c}} f(x) d x=Q\left(\frac{\bar{\tau}_{b c}-\bar{\tau}_{b r}}{\theta_{2}-\theta_{1}}\right) \\
& Q_{r}=Q \int_{\theta_{1}}^{\bar{\tau}_{b r}} f(x) d x=Q\left(\frac{\bar{\tau}_{b r}-\theta_{1}}{\theta_{2}-\theta_{1}}\right)
\end{aligned}
$$

\subsection{Market Equilibria}

Under the bilateral monopoly structure of the market, the highway operator has an advantage over the transit operator irrespective of the order of decisions on the prices and quality of service. In the first place, the highway operator can choose between two regimes, namely the interior solution with positive bus frequency and one without - the latter by setting the transit toll at a prohibitive level. The highway operator will choose the regime that gives the highest profit. Secondly, the highway operator can set the toll for the transit operator, whereas the transit operator cannot impose a charge on the highway operator.

The regime of zero bus frequency is considered as a reference case. It will be discussed in this section, before going into details of the formulation of possible interactions between the two operators under the second regime with a positive bus service frequency. The highway operator's profit in the case of no transit service will be compared with the equilibrium profits in the games followed. If the equilibrium profit is less than that in the zero bus frequency regime, the positive bus frequency regime will be considered non-optimal. The highway operator will then choose the no transit service scenario instead. The highway operator will, however, often prefer to allow a transit service on the highway. The total profit 
extracted by the two operators together will then typically be higher, as price and quality differentiation becomes possible (recall the heterogeneity of users). Provided the highway operator succeeds in extracting sufficient revenues from the transit operator through the transit toll, the highway operator's profits may therefore be higher than in absence of transit.

Under the second regime, four games will be formulated to determine market equilibria. Games A and B are sequential games, representing the situations when one of the operators can make the decisions before another, taking into account the response of the other operator, i.e. one of them is the leader of a Stackelberg game and the other the follower. Game A models the situation when the highway operator is the leader who can decide on the tolls before the transit operator decide on the fare and frequency. Game B models the reverse situation when the transit operator is the leader and the highway operator the follower. Game $\mathrm{C}$ is a simultaneous Nash game, in which there is no leader or follower position and both operators will make the decisions simultaneously, taking the correctly predicted decision of the other player as given. Game D is a two-stage game, to model the situation when the supply decision (frequency of service) is inflexible which has to be made before the decisions on fare and tolls.

Our motivation for considering these four games is our desire to illustrate how strongly the nature of competition - i.e., the game played - can affect the outcomes on the type of market we consider. We leave the question towards the likeliness of the various games adequately representing behaviour on real markets largely untouched, although some comments will be made as the discussion proceeds.

A final reference case to be considered is the case of a merging of the highway and transit operators or, in other words, the monopoly case with only one service provider providing both the highway and the transit service. This case will be discussed at the end of this section.

\subsubsection{The case without transit service}

Assuming that there is no transit service, users can only choose to drive or take the virtual mode. The cut-off VOT at which the users are indifferent between the two modes is at $\bar{\tau}_{c r}$, where the generalised costs of travelling on the two modes are equal:

$$
\begin{aligned}
& G_{c}\left(\bar{\tau}_{c r}\right)=G_{r}\left(\bar{\tau}_{c r}\right) \\
& f_{c}+T_{c} \bar{\tau}_{c r}+t_{c}=f_{r}+T_{r} \bar{\tau}_{c r} \\
& \bar{\tau}_{c r}=\frac{t_{c}+f_{c}-f_{r}}{T_{r}-T_{c}}
\end{aligned}
$$


The profit function of the highway operator is a function of the toll for private vehicles as follows:

$$
\pi_{h}\left(t_{c}\right)=t_{c} F_{c}\left(t_{c}\right)-C_{v h} F_{c}\left(t_{c}\right)-C_{f h}
$$

The expected number of private vehicle users will be

$$
F_{c}=Q\left(\frac{\theta_{2}-\bar{\tau}_{c r}}{\theta_{2}-\theta_{1}}\right)
$$

By applying the first order condition, the optimal toll for private vehicles can be determined as

$$
t_{c}^{*}=\frac{\theta_{2}\left(T_{r}-T_{c}\right)+C_{v h}-f_{c}+f_{r}}{2}
$$

The maximised profit will be

$$
\pi_{h}^{*}=t_{c}^{*} F_{c}-C_{v h} F_{c}-C_{f h}
$$

\subsubsection{Game A-highway operator as the leader}

Game A represents the case where the highway operator can decide on the tolls before the transit operator decides on the fare and frequency. As the leader of the game, the highway operator will consider the reaction function of the follower, i.e. the optimised fare and frequency for the transit operator given the toll charges. The equilibrium can be obtained by backward induction. The transit operator will maximise profit subject to the capacity constraint. The reaction function of the follower of the game (the transit operator) results from the following maximisation problem:

Maximise

$$
\pi_{b}\left(f_{b}, F_{b} \mid t_{b}, t_{c}\right)=f_{b} Q_{b}\left(f_{b}, F_{b}, t_{c}\right)-C_{v b} F_{b}-C_{f b}-F_{b} t_{b}
$$

subject to

$$
Q_{b}\left(f_{b}, F_{b}, t_{c}\right) \leq F_{b} H_{b}
$$

where $Q_{b}$ follows the demand equilibrium conditions and $H_{b}$ is the bus capacity of transit service. The corresponding Lagrangian formulation for this program is given by: 


$$
\begin{aligned}
\ell \pi_{b}\left(f_{b}, F_{b} \mid t_{b}, t_{c}\right)= & -f_{b} Q_{b}\left(f_{b}, F_{b}, t_{c}\right)+C_{v b} F_{b}+C_{f b}+F_{b} t_{b} \\
& +\lambda_{b}\left(Q_{b}\left(f_{b}, F_{b}, t_{c}\right)-F_{b} H_{b}\right)
\end{aligned}
$$

where $\lambda_{b}\left(\lambda_{b} \geq 0\right)$ is the Lagrangian multiplier associated with the bus capacity constraint. The associated optimality conditions are:

$$
\begin{aligned}
& \frac{\partial \ell \pi_{b}}{\partial f_{b}}=0 \\
& \frac{\partial \ell \pi_{b}}{\partial F_{b}}=0 \\
& Q_{b}\left(f_{b}, F_{b}, t_{c}\right)-F_{b} H_{b} \leq 0 \\
& \lambda_{b}\left(Q_{b}\left(f_{b}, F_{b}, t_{c}\right)-F_{b} H_{b}\right)=0 \\
& \lambda_{b} \geq 0
\end{aligned}
$$

The derivatives of the variables in the above model are shown in Appendix A. Denote the solutions to the above equations by $f_{b}^{*}, F_{b}^{*}$ and $\lambda_{b}^{*}$.

Although there is no explicit solution to the above optimisation problem, intuition can provide some insights on how the transit operator will react. The reaction of the transit operator will depend on the combination of the toll charges. The higher the transit toll, the higher the fare the transit operator will charge, and the less frequent service he can offer due to the reduced demand (provided the bus capacity constraint is binding). The higher the private vehicle toll, the higher the fare the transit operator can charge and the service frequency has to be enough to meet the demand.

Given the behaviour of the transit operator and the demand equilibrium condition, the objective of the highway operator is to maximise profit as follows:

Maximise

$$
\pi_{h}\left(t_{b}, t_{c}\right)=F_{b}^{*} t_{b}+F_{c}\left(f_{b}^{*}, F_{b}^{*}, t_{c}\right) t_{c}-C_{v h}\left(F_{b}^{*}+F_{c}\left(f_{b}^{*}, F_{b}^{*}, t_{c}\right)\right)-C_{f h}
$$

The optimality conditions are

$$
\frac{\partial \pi_{h}}{\partial t_{b}}=0
$$


$\frac{\partial \pi_{h}}{\partial t_{c}}=0$

and $F_{c}$ follows the demand equilibrium conditions.

Again, there is no explicit solution to the highway operator's optimisation problem, but intuition can provide some ideas about the highway operator's optimal strategy given the behaviour of the transit operator. To maximise profit, the highway operator will try to charge as high as possible, taking into account the demand equilibrium conditions, and implicitly the transit operators' profitability. To remain competitive to transit service, the private vehicle toll cannot be too high. To maintain the transit operator in business so that profits can be made from transit operator as well as from private vehicles, the transit toll cannot be too high. The breakeven case for the transit operator is considered as the implicit limit imposed to the transit toll. These two factors will create a boundary for the toll charges, and hence for the profitability for the highway operator in the game.

\subsubsection{Game B-transit operator as the leader}

Game B represents the reverse case of Game A: the transit operator now decides on the fare and frequency of service, before the highway operator decides on the tolls. This set-up appears to be less realistic than the one in Game A (it is hard to imagine a transit operator announcing or even commencing operations before knowing how much to pay for the use of the infrastructure), but it is interesting to consider it, both in order to be able to illustrate how strongly the outcomes in our market depend on the type of interaction between the players, and for the sake of completeness of our exposition. As in Game A, the equilibrium can be determined by backward induction. Consider the profit function of the highway operator,

$$
\pi_{h}\left(t_{b}, t_{c} \mid f_{b}, F_{b}\right)=F_{b} t_{b}+F_{c}\left(f_{b}, F_{b}, t_{c}\right) t_{c}-C_{v h}\left(F_{b}+F_{c}\left(f_{b}, F_{b}, t_{c}\right)\right)-C_{f h}
$$

Given the fare and service frequency, this function is unbounded without the consideration of the implicit constraints associated with the operation of the transit service, including the capacity and profitability constraints. The first term of the function $\left(F_{b} t_{b}\right)$ is the revenue from the toll charge on transit vehicles, which will be unbounded if these implicit constraints are not considered. Not considering these constraints is definitely unreasonable, because it would result in an unlimited toll for transit.

In the case of the positive bus frequency regime being more profitable, and taking the implicit constraints into consideration, the highway operator will maximise profit subject to the capacity and profitability constraints. The reaction function of the highway operator then follows from: 
Maximise

$\pi_{h}\left(t_{b}, t_{c} \mid f_{b}, F_{b}\right)=F_{b} t_{b}+F_{c}\left(f_{b}, F_{b}, t_{c}\right) t_{c}-C_{v h}\left(F_{b}+F_{c}\left(f_{b}, F_{b}, t_{c}\right)\right)-C_{f h}$

subject to

$Q_{b}\left(f_{b}, F_{b}, t_{c}\right) \leq F_{b} H_{b}$

$\pi_{b}\left(f_{b}, F_{b}, t_{c}\right) \geq 0$

where $Q_{b}$ and $F_{c}$ follows the demand equilibrium conditions. The optimal private and transit tolls can be determined based on the above formulation and the breakeven profit constraint for the transit operator.

The maximum transit toll will be bounded by the profitability constraint and the equilibrium conditions, as derived in Appendix B, and is as follows:

$t_{b}^{*}=\frac{f_{b} Q_{b}\left(f_{b}, F_{b}, t_{c}\right)-C_{v b} F_{b}-C_{f b}}{F_{b}}$

This will be the optimal transit toll, because this is the point at which the transit operator can only obtain breakeven profits and will maintain in operation.

Substitute eqn. (39) into eqn. (36),

$$
\begin{aligned}
\pi_{h}\left(t_{b}, t_{c} \mid f_{b}, F_{b}\right) & =f_{b} Q_{b}\left(f_{b}, F_{b}, t_{c}\right)-C_{v b} F_{b}-C_{f b}+F_{c}\left(f_{b}, F_{b}, t_{c}\right) t_{c} \\
& -C_{v h}\left(F_{b}+F_{c}\left(f_{b}, F_{b}, t_{c}\right)\right)-C_{f h}
\end{aligned}
$$

The first order condition determines the optimal toll for private vehicles.

$$
\begin{aligned}
& \frac{\partial \pi_{h}}{\partial t_{c}}=f_{b} \frac{\partial Q_{b}}{\partial t_{c}}+F_{c}+\left(t_{c}-C_{v h}\right) \frac{\partial F_{c}}{\partial t_{c}}=0 \\
& t_{c}^{*}=\frac{1}{2}\left[\theta_{2}\left(T_{b}+\frac{1}{2 F_{b}}-T_{c}\right)-f_{c}+2 f_{b}+C_{v h}\right]
\end{aligned}
$$

However, subject to the capacity constraint, there is an upper bound for the toll for private vehicles as follows: 


$$
\begin{aligned}
t_{c}^{U B} & =\left(T_{b}+\frac{1}{2 F_{b}}-T_{c}\right) \\
& {\left[F_{b} H_{b}\left(\frac{Q}{\theta_{2}-\theta_{1}}\right)^{-1}+\left(f_{b}-f_{r}\right)\left(T_{r}-T_{b}-\frac{1}{2 F_{b}}\right)^{-1}-\left(f_{c}-f_{b}\right)\left(T_{b}+\frac{1}{2 F_{b}}-T_{c}\right)^{-1}\right] }
\end{aligned}
$$

The optimal toll charge for private vehicles should be the minimum of $t_{c}^{*}$ and $t_{c}^{U B}$. However, there is another limit for the toll charge for private vehicles, due to the underlying assumption of the VOT following a uniform distribution as stated in eqn. (13). If the toll charge is above $t_{c}^{\max }$ as shown below, the cut-off VOT value $\left(\bar{\tau}_{b c}\right)$ will become out of the range of the distribution, i.e. the demand of private vehicles will be zero. Thus, if $\operatorname{Min}\left\{t_{c}^{*}, t_{c}^{U B}\right\}>t_{c}^{\max }$, the optimal toll should be $t_{c}^{\max }$ instead. Otherwise, the optimal toll remains to be $\operatorname{Min}\left\{t_{c}^{*}, t_{c}^{U B}\right\}$.

$t_{c}^{\max }=\left(T_{b}+\frac{1}{2 F_{b}}-T_{c}\right) \theta_{2}+f_{b}-f_{c}$

The derivation of the expressions for $t_{c}^{*}, t_{c}^{U B}$ and $t_{c}^{\max }$ is illustrated in Appendix B. Substitute the optimal $t_{c}$ value back into eqn. (39), the optimal transit toll can then obtained. The maximised profit for the highway operator thus obtained will be compared with the reference case of no transit service, to validate the assumption that the regime of positive bus frequency will be more profitable for the highway operator.

The transit operator is a customer as well as a competitor to the highway operator. Intuitively the highway operator's optimal strategy is to charge the private vehicles just low enough to attract all the users with higher VOT values not attracted to the transit service. At the same time, he can charge the transit operator the highest possible toll such that the transit operator can only obtain breakeven profits based on the assumption that this is the bottom line to stay in business. In this way, the highway operator can extract all pre-toll profits from the transit operator, without distorting the demand equilibrium modal splits (as the transit operator is in this game committed to the fare and frequency chosen). Under this strategy, the transit operator can only expect breakeven profits, no matter what decisions on the fare and frequency are made.

As the leader of the game and knowing that only breakeven profit can be expected, the transit operator requires a secondary objective in order to choose a determinate level of quality (frequency) and fare. As in a monopoly situation studied by Dodgson and Katsoulacos (1988), a reasonable secondary objective for a monopolist would be to choose the quality of service which maximises profits from the maximum patronage. The effect of a secondary objective as such entails a maximum service frequency and a correspondingly low fare. 


\subsubsection{Game C-Nash game}

The Nash game represents the case of both the operators making their decisions simultaneously, both treating the other player's (correctly predicted) decision(s) as given. In this case, reaction functions of both operators will be considered. The equilibrium point is represented by a decision vector, consisting of the optimal tolls, fare and frequency, such that one operator's profit is maximised given the decisions of the other (and vice versa).

The reaction function of the transit operator is the same as that in Game A, as implied by eqns. (24) and (25). On the other hand, the reaction function of the highway operator is the same as that in Game B, as implied by eqns. (36) to (38). The Nash equilibrium satisfies both reaction functions.

\subsubsection{Game D-capacity as the long run decision and price as the short run}

In Game D, we consider the case when the service frequency is inflexible in the short run, while fare and tolls are flexible. This situation is formulated as a two-stage game, with the fare and tolls determined in the second stage and the frequency in the first stage. To determine the equilibrium by backward induction, the second stage is first considered. In this stage, the highway operator has chosen the frequency of service already. The two operators have to determine the fare and tolls simultaneously taking into consideration of the chosen frequency and the reaction function of each other.

The highway operator's decision problem is basically the same as that in Games B and C, but the frequency of transit service is known before the fare, i.e., maximising the profit subject to the capacity and profitability constraints. The highway operator's reaction function results from:

Maximise

$$
\pi_{h}\left(t_{b}, t_{c} \mid f_{b}, \bar{F}_{b}\right)=\bar{F}_{b} t_{b}+F_{c}\left(f_{b}, \bar{F}_{b}, t_{c}\right) t_{c}-C_{v h}\left(\bar{F}_{b}+F_{c}\left(f_{b}, \bar{F}_{b}, t_{c}\right)\right)-C_{f h}
$$

subject to

$$
\begin{aligned}
& Q_{b}\left(f_{b}, \bar{F}_{b}, t_{c}\right) \leq \bar{F}_{b} H_{b} \\
& \pi_{b}\left(f_{b}, \bar{F}_{b}, t_{c}\right) \geq 0
\end{aligned}
$$

where $Q_{b}$ and $F_{c}$ follows the demand equilibrium conditions, and $\bar{F}_{b}$ is the given frequency of service. The solution to the highway operator's optimization problem will be the same as in Games B and C, as depicted in eqns. (39) to (44). 
The transit operator's decision problem is to optimise the fare taking into consideration the highway operator's reaction function and the previously chosen frequency of service, i.e.:

Maximise

$\pi_{b}\left(f_{b} \mid t_{b}, t_{c}, \bar{F}_{b}\right)=f_{b} Q_{b}\left(f_{b}, \bar{F}_{b}, t_{c}\right)-C_{v b} \bar{F}_{b}-C_{f b}-\bar{F}_{b} t_{b}$

subject to

$Q_{b}\left(f_{b}, \bar{F}_{b}, t_{c}\right) \leq \bar{F}_{b} H_{b}$

where $\bar{F}_{b}$ is the chosen frequency of service. The corresponding Lagrangian formulation for this program is given by:

$$
\begin{aligned}
\ell \pi_{b}\left(f_{b} \mid t_{b}, t_{c}, \bar{F}_{b}\right)= & -f_{b} Q_{b}\left(f_{b}, \bar{F}_{b}, t_{c}\right)+C_{v b} \bar{F}_{b}+C_{f b}+\bar{F}_{b} t_{b} \\
& +\lambda_{b}\left(Q_{b}\left(f_{b}, \bar{F}_{b}, t_{c}\right)-\bar{F}_{b} H_{b}\right)
\end{aligned}
$$

where $\lambda_{b}\left(\lambda_{b} \geq 0\right)$ is the Lagrangian multiplier associated with bus capacity.

The optimal conditions are as follows:

$\frac{\partial \ell \pi_{b}}{\partial f_{b}}=0$

$Q_{b}\left(f_{b}, \bar{F}_{b}, t_{c}\right)-\bar{F}_{b} H_{b} \leq 0$

$\lambda_{b}\left(Q_{b}\left(f_{b}, \bar{F}_{b}, t_{c}\right)-\bar{F}_{b} H_{b}\right)=0$

$\lambda_{b} \geq 0$

The optimal fare can be one of the following four cases:

Case 1: $\lambda_{b}=0, F_{c}>0$

$$
f_{b}^{*}=\frac{\left(f_{c}+t_{c}\right)\left(T_{b}+\frac{1}{2 \bar{F}_{b}}-T_{c}\right)^{-1}+f_{r}\left(T_{r}-T_{b}-\frac{1}{2 \bar{F}_{b}}\right)^{-1}}{2\left[\left(T_{b}+\frac{1}{2 \bar{F}_{b}}-T_{c}\right)^{-1}+\left(T_{r}-T_{b}-\frac{1}{2 \bar{F}_{b}}\right)^{-1}\right]}
$$


Case 2: $\lambda_{b}=0, F_{c}=0$

$$
f_{b}^{*}=\frac{1}{2}\left(T_{r}-T_{b}-\frac{1}{2 \bar{F}_{b}}\right)\left[\theta_{2}+f_{r}\left(T_{r}-T_{b}-\frac{1}{2 \bar{F}_{b}}\right)^{-1}\right]
$$

Case 3: $\lambda_{b}>0, F_{c}>0$

$$
f_{b}^{*}=\frac{\left(f_{c}+t_{c}\right)\left(T_{b}+\frac{1}{2 \bar{F}_{b}}-T_{c}\right)^{-1}+f_{r}\left(T_{r}-T_{b}-\frac{1}{2 \bar{F}_{b}}\right)^{-1}-\bar{F}_{b} H_{b}\left(\frac{Q}{\theta_{2}-\theta_{1}}\right)^{-1}}{\left(T_{r}-T_{b}-\frac{1}{2 \bar{F}_{b}}\right)^{-1}+\left(T_{b}+\frac{1}{2 \bar{F}_{b}}-T_{c}\right)^{-1}}
$$

Case 4: $\lambda_{b}>0, F_{c}=0$

$$
f_{b}^{*}=\left(T_{r}-T_{b}-\frac{1}{2 \bar{F}_{b}}\right)\left[\theta_{2}+f_{r}\left(T_{r}-T_{b}-\frac{1}{2 \bar{F}_{b}}\right)^{-1}-\bar{F}_{b} H_{b}\left(\frac{Q}{\theta_{2}-\theta_{1}}\right)^{-1}\right]
$$

The optimal fare will be the one that gives rise to the highest profit among the above four cases for the transit operator. Details of the derivation of the optimal fares are shown in Appendix C. The equilibrium for this subgame will be at the point where, for a given frequency of service, both the operators' reaction functions are satisfied. Since the highway operator's reaction function will induce a breakeven profit for the transit operator, at equilibrium, the transit operator's optimised profit is also zero.

The first stage game will be the decision problem for the transit operator to optimise the frequency given the equilibrium conditions in the second stage. In this case, the transit operator's profit will always be zero but the highway operator's profit will depend on the transit operator's decision on the service frequency. As in Game B, the transit operator requires a secondary objective in order to choose the frequency of service in the first stage. We use the same secondary objective of choosing the frequency of service at which the patronage is maximised at breakeven profit.

2.2.6. The monopoly case - only one service provider providing the highway and transit service

When only one service provider is considered, the objective of the operator will be to maximise the total profits subject to the capacity constraints, i.e.:

Maximise 


$$
\begin{aligned}
\pi_{t} & =\pi_{h}+\pi_{b} \\
& =t_{c} F_{c}\left(t_{c}, f_{b}, F_{b}\right)+f_{b} Q_{b}\left(t_{c}, f_{b}, F_{b}\right)-C_{v h}\left(F_{b}+F_{c}\left(t_{c}, f_{b}, F_{b}\right)\right)-C_{v b} F_{b}-C_{f h}-C_{f b}
\end{aligned}
$$

subject to

$Q_{b}\left(f_{b}, F_{b}, t_{c}\right) \leq F_{b} H_{b}$

where $Q_{b}$ and $F_{c}$ follow the demand equilibrium conditions.

The corresponding Lagrangian formulation for this program is given by:

$$
\begin{aligned}
\ell \pi_{t}= & -t_{c} F_{c}\left(f_{b}, F_{b}, t_{c}\right)-f_{b} Q_{b}\left(f_{b}, F_{b}, t_{c}\right)+C_{v h}\left(F_{b}+F_{c}\left(f_{b}, F_{b}, t_{c}\right)\right) \\
& +C_{v b} F_{b}+C_{f h}+C_{f b}+\lambda_{b}\left(Q_{b}\left(f_{b}, F_{b}, t_{c}\right)-F_{b} H_{b}\right)
\end{aligned}
$$

The optimality conditions are:

$$
\begin{aligned}
& \frac{\partial \ell \pi_{t}}{\partial f_{b}}=\left(C_{v h}-t_{c}\right) \frac{\partial F_{c}}{\partial f_{b}}+\left(\lambda_{b}-f_{b}\right) \frac{\partial Q_{b}}{\partial f_{b}}-Q_{b}=0 \\
& \frac{\partial \ell \pi_{t}}{\partial F_{b}}=\left(C_{v h}-t_{c}\right) \frac{\partial F_{c}}{\partial F_{b}}+\left(\lambda_{b}-f_{b}\right) \frac{\partial Q_{b}}{\partial F_{b}}+C_{v h}+C_{v b}-\lambda_{b} H_{b}=0 \\
& \frac{\partial \ell \pi_{t}}{\partial t_{c}}=\left(C_{v h}-t_{c}\right) \frac{\partial F_{c}}{\partial t_{c}}+\left(\lambda_{b}-f_{b}\right) \frac{\partial Q_{b}}{\partial t_{c}}-F_{c}=0 \\
& Q_{b}\left(f_{b}, F_{b}, t_{c}\right)-F_{b} H_{b} \leq 0 \\
& \lambda_{b}\left(Q_{b}\left(f_{b}, F_{b}, t_{c}\right)-F_{b} H_{b}\right)=0 \\
& \lambda_{b} \geq 0
\end{aligned}
$$

The derivatives of the variables in the above model are derived in Appendix D.

\section{Numerical Results and Interpretation}

In order to investigate the comparative static equilibrium properties of the games described in the previous section, we develop a numerical simulation model. Table 3 shows the parameter values used. The numerical equilibrium solutions to the various games are summarised in Table 4. 


\subsection{The case without transit service}

If there is no transit service operating on the highway, the profit for the highway operator as a function of the toll is parabolic, due to the elasticity of demand caused by the availability of the virtual mode. The maximum profit is $\$ 32,210$ per hour at a toll charge of $\$ 40.5$.

\subsection{Game A-highway operator as the leader}

Figure 1 shows the profits for both operators as a function of various levels of the two toll levels, of course taking into account the private vehicle users' and transit operator's reactions to these tolls. As expected, the maximum toll for profit maximisation that the highway operator should charge is constrained by the transit capacity, and of course by demand equilibrium conditions.

As shown in Figure 1, the highway operator's profit increases as the private vehicle toll increases, but only up to a certain toll value ( $\$ 40$ in this case). This reflects that increasing the private vehicle toll increases the profit per vehicle but at the same time reduces the demand of private vehicles.

On the other hand, as the transit toll increases, the transit operator will respond by increasing the fare and providing just enough capacity to satisfy the demand. When the transit toll is beyond a certain value ( $\$ 2,162$ in this case), the profitability constraint for the transit operator will become binding. The highway operator cannot increase the transit toll any further. Otherwise, the transit operator will be out of business.

Given the reaction of the transit operator, the optimal tolls will be the tolls at the equilibrium point shown in Figure 1 ( $\$ 40$ for private vehicle and $\$ 2,162$ for transit respectively). The transit operator will be able to make positive profit, although it is significantly less than the highway operator's profit.

The highway operator's profit of $\$ 52,362$ is higher than the $\$ 32,210$ applying in the no transit service case. The regime of positive bus frequency is therefore more profitable for the highway operator, and will therefore be his preferred outcome. The higher profit is the consequence of the price and quality differentiation that becomes possible on the private road with transit services in operation, and that extracts more total revenues from the users because of the dispersion in preferences that exists. The highway operator subsequently succeeds in skimming most of the transit operator's pre-toll profits, and hence benefits from this price and quality differentiation.

\subsection{Game B-transit operator as the leader}

As discussed in Section 2.2.3, when the transit operator is the leader, the highway operator can react to the chosen fare and frequency by charging the maximum transit toll, such that the 
transit operator can only obtain breakeven profits. Thus the profit for the transit operator will always be zero. On the other hand, the corresponding profit for the highway operator will depend on the chosen fare and service frequency. The contours of the highway operator's optimised profit as a function of the transit operator's fare and frequency are shown in Figure 2. The corresponding optimised toll values are plotted in Figure 3.

As shown in Figure 3, the higher the transit fare (for a given frequency), the higher the optimal private vehicle toll. This is because when transit operator is charging a high fare, driving can still be an attractive mode even though the toll is high. For a given transit fare, the optimal private vehicle toll first increases with the increase in service frequency and then remains stable. The toll first increases because with a higher frequency of service, transit becomes more attractive due to the lower waiting time, and fewer users will be driving. In order to maintain its profit, the highway operator will have to charge the private vehicles a higher toll. When the frequency of service is so high that all users are attracted to transit service, there is no point to increase the private vehicle toll any further. The private vehicle toll should be just high enough to keep them off the road, while the transit toll should be maximised such that the transit operator can only obtain breakeven profits.

As shown in Figure 3, for a given frequency of service, the optimal transit toll increases with increase in fare. This is because the higher the fare, the higher the marginal profit and the higher the transit operator's breakeven toll charge. For the same transit fare, the optimal transit toll first remains stable but decreases afterwards when the service frequency becomes higher and higher. This is because the increase in service frequency will eventually attract all users, and when the transit operator is over-supplying capacity, the breakeven toll will become lower.

As a result, the highway operator is better off when the transit fare is relatively high and service frequency not too high, in which case both private vehicles and transit service will use the highway and the highway operator's profit can then be maximised. However, as the follower of the game, the highway operator has no control on the transit operator's decisions on the fare and frequency. The equilibrium can be any point in the breakeven profit space of the transit operator.

The transit operator will require a secondary objective in order to determine the fare and frequency. Considering maximising profits from the maximum patronage level of output as the secondary objective, maximising patronage entails a maximum service frequency and a correspondingly low fare as shown in Figure 4. With this secondary objective, the highway operator's profit will almost diminish to zero. The transit operator will provide the most frequent service (about 120 per hour) at a relatively low price (\$10). These extreme values of frequency and fare for the test case are determined based on the assumptions as stated in 
eqns. (5) and (6). As a result, as shown in Table 4, both operators will end up having breakeven profit.

This solution is not really the equilibrium, because the highway operator can give up the regime of allowing positive bus frequency and increase profits by choosing a transit toll at a prohibitive level. Knowing that the strategy to diminish the highway operator's profit is not viable, the transit operator will have to choose a fare and frequency such that the highway operator will be just better off than without transit service. If we take the no transit service case as the bottom line of the highway operator's profit, we can work backwards by numerical search in the solution space to obtain the optimal strategy for the transit operator. The transit operator will choose a combination of fare and frequency such that the highway operator's profit is just above that in the case of no transit service and at the same time, the patronage on the transit service is maximised. As shown in Table 4, the optimal solution for the transit operator will be to provide service at a fare of $\$ 15$ and frequency of 61 per hour. The maximised profit for the highway operator will be slightly higher than in the no transit service case. Again, the regime of positive bus frequency is more profitable for the highway operator. The maximised patronage will be 3,440 passengers per hour.

\subsection{Game C-Nash game}

Now let us consider the case when both operators have to make the decisions on the tolls, fare and frequency simultaneously. The equilibrium will be within the region where the reaction functions of the transit operator in Game A (as implied by eqns. (24) and (25)) and the highway operator in Game B (as implied by eqns. (36) to (38)) coincide. We will explore the possible combinations of the profits of the two operators in the two reaction functions and determine the set of fare, tolls, frequency and profits common to the two reaction functions. This common set represents all the possible Nash equilibrium points because the transit operator is best responding to the given tolls (Game A) and at the same time, the highway operator is best responding to the given fare and frequency (Game B). The two-dimensional profit space of the two operators is illustrated in Figure 5. The profit space of Game A is represented by the shaded area while the profit space of Game B is along the y-axis. The intersection of the two spaces is along the $\mathrm{y}$-axis from Point $\mathrm{C}$ to the origin, i.e. we have multiple Nash equilibria in this case. The fact that no unique Nash equilibrium exists results from the fact that without a secondary objective, the transit operator's pay-off is independent to his own behaviour (as illustrated by the profit space of Game B). The transit operator's equilibrium profit is always zero because all the pre-toll profits are extracted by the highway operator. On the other hand, the highway operator's profit depends on how much pre-toll profits are extracted from the transit operator and how much profits are obtained from private vehicles. There is no compelling evidence that one combination of fare, tolls and frequency will dominate the other in the set of Nash equilibrium points. Nevertheless, it is conceivable that the most probable Nash equilibrium is at Point $\mathrm{C}$ where the highway operator's profit is 
the highest among all the responsive combination of fare and frequency by the transit operator that leads to the same maximum zero profit.

At Point C, the optimal tolls are $\$ 41$ and $\$ 2,521$ respectively for private vehicle and transit operator respectively. The highway operator's profit of $\$ 49,054$ is higher than $\$ 32,210$ in the no transit service case. The regime of positive bus frequency is more profitable for the highway operator. The transit operator will provide service at a fare of $\$ 47$ and frequency of about 11 bus trips per hour.

\subsection{Game D-capacity as the long run decision and price as the short run}

Finally, when transit frequency is rigid in the short run and hence should be announced before the actual game is played, the highway operator's decision problem is basically the same as that in Game B and C, except that the frequency of transit service is known before the fare. However, prior knowledge of the frequency of service might not provide the highway operator any advantage at all, since the fare has yet to be decided simultaneously with the tolls in the second stage. The points on the dashed line in the earlier Figure 2 represent the highest possible profit for the highway operator given the frequency. A point on this dotted line can be a possible equilibrium point only if the maximised profit for the transit operator given the tolls at the point is also zero. The equilibrium point is not necessarily on this line.

In Stage 2, for a given frequency of service, the highway operator will determine the tolls such that the transit operator's maximised profit given the tolls is zero. If there are multiple points where these conditions are satisfied, the secondary objective will be applied to determine the optimal point for the given frequency. In Stage 1, the transit operator will apply the secondary objective again to choose among all the equilibrium points determined in Stage 2 and chooses the frequency of service such that the patronage is maximised.

The patronage can be maximised at a fare of $\$ 21$ and a service frequency of 56 per hour. The maximised patronage will be 3,086 passengers per hour. The corresponding profit for the highway operator will be $\$ 47,244$ with the optimised toll values of $\$ 18.6$ and $\$ 855$ for private vehicle and transit respectively. Since the profit for the highway operator is greater than the no transit service case, the regime of positive bus frequency is more profitable in this game.

\subsection{The monopoly case - only one service provider providing the highway and transit} service

Assuming that there is only one service provider providing the highway and the transit service, there will not be any toll charge for transit. The toll charge for private vehicles $(\$ 40)$ is more or less the same as in the case of no transit service. The optimised fare for transit 
service is $\$ 38$ and service frequency will be 34 per hour. The maximum total profit is $\$ 67,491$ which is the highest among all cases examined.

With the toll charge of $\$ 40$ for private vehicles, private vehicle will in fact be tolled off the road. This maximum profit is generated from passengers using the transit service only. This observation is case dependent, however, and is considered not generally true. In the hypothetical case constructed, the marginal operating cost for carrying traffic on the highway is higher than the marginal operating cost for carrying passengers on transit. If both services are to be offered by the same operator, it will be more economical to carry passengers by buses rather than allowing them to drive due to the higher profit margin in providing transit service.

\subsection{Summary of results}

As shown in Table 4, different sequences of moves in the formulated games can result in very different market equilibria. Their differences in terms of profits and optimal strategies will be investigated one by one. The resulting profits at equilibrium are plotted in Figure 5. The optimal fare, frequency and toll values at equilibrium can be found in Table 4.

Comparing the equilibrium profits in Game A and Game B, a second mover advantage is observed for the transit operator. As the leader of the game in Game B, the transit operator can only expect breakeven profits. In Game A, when the transit operator is the follower instead of the leader, the profit is positive. Comparing the profits in Game B and Game C, the transit operator also has an advantage being a follower as compared with being in 'equal' position with the other player in the Nash game. However, in Game D, being able to make the decision on the frequency of service first will not provide an advantage to the transit operator. The expected profit is still zero.

The highway operator, in contrast, has an advantage as the first mover rather than the second or a simultaneous mover. Comparing the equilibrium profits in Game A with Games B and C, the highway operator has highest profit in Game A, i.e., when being the leader of the game.

In terms of quality of transit service, the equilibrium in Game B will offer the best (with the lowest fare and highest frequency), while the Nash game (Game C) offers the worst. Nash behaviour will result in a higher fare, lower frequency and higher tolls at equilibrium, compared with the leader-follower and the two-stage games.

The reason for the higher fare, lower frequency and higher tolls in the Nash game (Game C) is, to a certain extent, due to the effect of double marginalisation as a result of the bilateral monopoly structure. Both highway infrastructure and transit vehicles are required to provide transit service. The highway operator provides the infrastructure, and the transit operator provides the vehicles. The highway operator derives profit only from the tolls (but not only 
from transit which is slightly different from a 'classic' bilateral case), and the transit operator derives profit only from the fare. In the leader-follower games or the two-stage game (Games A, B and D), the leader, to a certain extent, has the control on the properties of the solution. In Game A, the solution is characterised with relatively higher tolls because it will bring benefit to the leader - the highway operator. On the contrary, in Games B and D, the solution is characterised by relatively lower fare and higher frequency because it will bring higher patronage to the transit operator. In the Nash game, when both players have to make their decision simultaneously, the highway operator's behaviour is consistent with its behaviour as the leader but the transit operator's is not. This is because the transit operator knows that the tolls are going to be high and the only way to survive is to set the fare higher and provide less frequency of service. Knowing that the transit operator will do so, to maximise its profits, the highway operator will make sure all profits of the transit operator will be extracted. In this way, each operator ignores the adverse effect that raising its fare/tolls (and decreasing service frequency in transit's case) has on the other's profit.

The total profit in the monopoly case is of course higher than that in any of the four games formulated. The maximised profit is, perhaps somewhat unrealistically, entirely generated from transit service rather than private vehicle users. This is due to the parametrization of the hypothetical case, and is not considered to be generally true. Nevertheless, it can be verified that merging the two service providers can result in higher total profit than in the bilateral case.

\section{Welfare Implications}

\subsection{The welfare function}

In order to determine the welfare implications, a social cost function is first defined, which measures the total cost to the society in satisfying the given overall travel demand. An appropriate measure of social cost (Mohring, 1972) is the sum of the operating cost and the journey time weighted by the value of time. That is,

$$
\begin{aligned}
\text { Social Cost } & =\left(\begin{array}{c}
\text { Value of } \\
\text { Total Travel Time }
\end{array}\right)+\left(\begin{array}{c}
\text { Total } \\
\text { Operating Costs }
\end{array}\right) \\
& =\left[F_{c} T_{c}\left(\frac{\theta_{2}+\bar{\tau}_{b c}}{2}\right)+Q_{b}\left(T_{b}+\frac{1}{2 F_{b}}\right)\left(\frac{\bar{\tau}_{b c}+\bar{\tau}_{b r}}{2}\right)+Q_{r} T_{r}\left(\frac{\bar{\tau}_{b r}+\theta_{1}}{2}\right)\right]+ \\
& F_{c}\left(f_{c}+C_{v h}\right)+C_{f h}+F_{b} C_{v b}+C_{f b}+Q_{r} C_{v r}+C_{f r}
\end{aligned}
$$

In this case, the social cost also equals the total generalised cost minus the sum of profits, because the revenues cancel out with the toll charges and fares paid by users. 
Social Cost $=$ Total Generalised Cost - Total Profit

To maximise the net social benefit is equivalent to minimising the social cost, given the inelasticity of overall demand. The social cost in this case is a function of the equilibrium private vehicle toll, fares and frequency, including the fare of the virtual mode. It does not depend on the transit toll, because that will only affect the transfer of profits from the transit operator to the highway operator which has no effect on the social cost function defined above. On the other hand, the private vehicle toll, fares and frequency will affect the demand equilibrium (determined by the cut-off VOT values) which in turn affects the social cost.

\subsection{The social optimal case}

The social optimal solution, as shown in Table 3, is determined with the fare of the virtual included as a decision variable apart from the private vehicle toll, transit fare and frequency. Note that the profits for the highway and transit operator is shown as a joint profit because their respective profits depend on the transit toll which is not a decision variable in the social cost function. As mentioned above, the social cost does not depend on the transit toll as it is only a transfer of profits between the two operators. There are only two modes being used and private vehicles are tolled off in the social optimal solution. As in the monopoly case, this observation is considered case specific and is not generally true. As mentioned earlier, in the hypothetical case constructed, the marginal operating cost for carrying traffic on the highway is higher than the marginal operating cost for carrying passenger on the bus, even without considering the effect of congestion. In order to minimise the total social cost, it will be more economical to carry the travellers on the mode with lower per-user cost. In this case, transit and rail services are relatively cheaper as compared with driving. As long as there is enough capacity on the transit service/rail, which is not a constraint in this formulation, the optimal strategy is to put all passengers on the more cost-effective modes. Therefore, as shown in Table 3, the social optimal solution has low fares $(\$ 2.0$ and $\$ 4.6$ on rail and transit respectively) and high frequency (about 65 per hour). The private vehicle toll is just high enough to toll them off the road (\$2.1) which is even lower than the transit fare. The fares of the rail and transit are so low and their service frequencies are so high that private vehicle are not attractive anymore. In this way, the number of users attracted to the favourable modes for the society is maximised.

\subsection{The implications of the strategic interactions on social cost}

As shown in Table 3, Game B's equilibrium solution is nearest to the social optimal case among all the cases formulated. This is because of the assumption on the secondary objective of the transit operator in Game B and the transit mode being more cost-effective in this specific case. Maximising the patronage will result in lower fare, higher frequency and lower tolls. As a result, the equilibrium solution of Game B incurs lower social cost. The second nearest to the social optimal solution is Game $\mathrm{D}$, in which case the secondary objective of 
maximising patronage is also applied by the transit operator. In fact, in both Games B and D, private vehicles are tolled off the road, as in the social optimal solution. On the other hand, as a result of the interactions between the operators under different game structures, the resulting tolls and fare are higher in Games A and C. Hence, the resulting social costs in these games are also higher.

Therefore, depending on the game structure, the social cost at equilibrium will be different as a result of the strategic interactions between the operators. Whether a game structure is more favourable to the society depends on the operating cost structure of the transportation systems and the generalised cost parameters.

\section{Conclusions}

This paper studied a bilateral monopoly situation on a private highway, involving strategic interactions between the highway and transit operators. Four games were formulated, representing different sequences of moves in the determination of market equilibria.

Games A and B are leader-follower games, formulated to model the situation when one operator can or must make a move before the other, with the highway operator as the leader and the transit operator as the follower in Game A, and vice versa in Game B. Game C is the Nash game, in which both operators have to make their decisions simultaneously. Game D is a two-stage game, with the decision on frequency considered to be a long-term decision, which has to be made prior to the decision on prices.

A hypothetical case was constructed to test the games formulated. With a common primary objective of profit maximisation and patronage maximisation as the secondary objective for the transit operators, equilibria in the games were identified. The resulting equilibria appear to be quite different as a result of the different nature of interactions between the operators. The reference case of no transit service and the monopoly case of merging the operators as one service provider providing both the infrastructure and transit services were also investigated. The implications of the different possible equilibria on the social cost were also studied.

The results of the numerical analysis on the hypothetical case indicate that for those parameters, the transit operator would prefer to be the follower rather than the leader, but reversely for the highway operator. It is therefore unlikely that game B would be long-lived if the operators, through signalling or collusion, could somehow affect the very structure of the game that they are playing. The tolls and fare are the highest when both operators have to make their decisions simultaneously, and lowest when the transit operator is the leader. In this particular case, the solutions with lower fare and higher frequency of service (Game B and Game D) incur lower social costs and are considered more beneficial to the society. However, this appears to be a case specific observation as related to the parameterisation of 
the hypothetical case. With the variable operating cost per vehicle on the highway being higher than the variable cost per passenger on transit, transit is the more cost-effective mode for the society in our numerical example. Therefore, the solutions with higher patronage are more favourable to the social cost minimisation objective.

Our analysis thus illustrated that the outcomes on a bi-lateral monopoly market may strongly depend on the nature of the game that is being played. When designing institutional set-ups for transport markets with private supply, the government would thus face the challenge of identifying the possible consequences for the resulting nature of competition, predicting the effects on social welfare, and - if possible - adapt the design accordingly. How this should be done is an important question that was, however, outside the scope of the current paper. And this brings us to some further suggestions for future research.

\section{Suggestions for Further Research}

The ultimate aim of developing the modelling framework presented in this paper is to determine the possible market equilibria in a bilateral monopoly situation on a private highway and hence the optimal policy in the management of the highway. Due to the complications of the decision processes involved, a few key assumptions are made in order to simplify the model to a manageable level. Further research on extensions of the model are possible by variations of some of the key assumptions with a view to solving the problem more realistically.

Distribution of the value of time. The uniformity of the distribution of VOT assumed in the model is a simplification to enable the solutions to some of the games formulated to be determined analytically. More realistically, a log-normal type of distribution will be more appropriate, as VOT is a non-negative variable. Moreover, the log-normal distribution being skewed with a longer tail to the right can implicitly model the different degree of competition between the modes. The degree of competition between the lower cost modes (rail and bus) is probably stronger than that between the higher cost ones (bus and private vehicles). The question is how this modification on the distribution of VOT will affect our experimental results. Intuitively, the critical VOT for the choice in the more high-market segment will probably be well to the right of the peak in the distribution. The highway operator might be in a better position than in the uniform case. He can probably charge vehicle users relatively higher, as this hypothesis would imply that the resulting loss of toll revenues due to people switching to the bus would be smaller.

Effect of congestion. The effect of congestion is assumed to be absent in the models developed. Travel times are assumed to be constant - independent of the number of users on the mode. More realistically, the presence of congestion will have an effect on the travel time and hence the mode choice of users. In fact, previous study on congestion pricing by Verhoef and Small (1999) has shown that the presence of congestion severely complicates the analysis 
and analytical closed-form solutions might be unavailable. In this case, if the effect of congestion is to be considered, the operation management of the highway will be crucial to its impact on the equilibrium. For instance, important questions that arise include those whether the transit service and the private vehicles will suffer from congestion to the same extent, whether the transit service imposes disproportionally severe congestion effects on private cars, and whether any significant congestion effects between the subsequent services of the transit operator exist. The effect of the operation management policy on the congestion situation and its subsequent effect on the level of suffering from congestion for the three modes are issues worth to be studied.

Alternative pricing schemes. The analysis in this paper is based on a simple linear accesspricing scheme whereby a constant fee is levied for each vehicle trip. It would be worthwhile to study other pricing arrangement and its impact on the equilibrium tolls. For instance, the highway operator can charge the transit operator a fixed fee instead of the toll or in addition to the toll. In such case, the optimal policy is probably to extract all the transit operator's profit through the fixed fee. In this way, the highway operator will be able to replicate the maximum-profit monopoly outcome. Such pricing scheme is easier to monitor than uniform pricing which requires the highway operator to monitor the number of bus runs. Another possibility is for the highway operator to demand a share of the fare box revenues. But the drawback is the additional monitoring required.

Possibilities of collusion. Clearly the results from the study illustrate the mutual scope for (tacit) collusion. For the highway operator, this would increase profits while for the transit operator, this would often prevent profits from being zero. The possibilities for different forms of collusion and their impact on the equilibrium will be an interesting area to explore.

Further gaming analysis. The pricing and service quality decisions modelled by the games are effectively one-shot - each decision variable is decided once although the sequence of the decisions is not the same. More realistically, these decisions are made on a periodical basis rather than in one shot. Repeated games might be a possible way to model such situation and the results could be quite different, for instance because tacit collusion might arise.

\section{Acknowledgement}

This research described in this paper was substantially supported by a grant from the Research Grants Council of the Hong Kong Special Administrative Region, China (Project No. HKUST6033/02E). 


\section{References}

Banks, J. H., 1991. Effect of time-value distributions on transit headway optimisation. Journal of Advanced Transportation, Vol. 25, pp. 161-186.

Dodgson, J. S., and Katsoulacos, Y., 1988. Quality Competition in Bus Services. Journal of Transport Economics and Policy, Sep 1998, pp. 263-281.

Else, P. K., and James, T. J., 1995. Privatisation and the Quality of Rail Services. Transportation Research, 29A, pp. 387-400.

Mohring, H., 1972. Optimisation and Scale Economics in Urban Bus Transportation. American Econ Rev, 62, pp. 591-604.

Pedersen, P. A., 1998. Strategical Interactions within Transport Markets. Paper presented in the 8th WCTR held in Antwerp Belgium, 12-17 July, 1998.

Verhoef, Erik T., and Small, Kenneth A., 2000. Working Paper on Product Differentiation on Roads: Constrained Congestion Pricing with Heterogeneous Users.

Yang, H., Kong, H. K. and Meng, Q., 2001. Value-of-Time Distributions and Competitive Bus Services. Transportation Research Part E, 37, pp, 411-424. 


\section{Figure and Table Legend}

\section{List of Tables}

Table 1. Model parameters and variables

Table 2. Details of the hypothetical case in the numerical analysis

Table 3. Summary of results

\section{List of Figures}

Figure 1. Profits distribution in Game A

Figure 2. Highway operator's optimised profits in Game B

Figure 3. Highway operator's optimised tolls in Game B

Figure 4. Transit operator's expected patronage in Game B

Figure 5. The highway and transit operators' profit at equilibrium of various games

\section{List of Appendices}

Appendix A. Derivation of the derivatives in the demand equilibrium model

Appendix B. Derivation of optimal toll charges in Game B

Appendix C. Derivation of optimal transit fares in Game D

Appendix D. Derivation of derivatives for the monopoly case - only one service provider providing the highway and transit service 
Table 1. Model parameters and variables

\begin{tabular}{|c|c|c|c|c|c|}
\hline Party & Objective & Decision Variables & $\begin{array}{l}\text { Functional Form of Objective } \\
\text { Function }\end{array}$ & Exogenous Variables & Function Parameters \\
\hline $\begin{array}{l}\text { Highway } \\
\text { operator }(h)\end{array}$ & $\begin{array}{l}\text { Maximise } \\
\text { profit }\end{array}$ & $\begin{array}{l}\text { - Toll charge for } \\
\text { private vehicle } \\
\left(t_{c}\right) \\
\text { - Toll charge for } \\
\text { transit vehicle }\left(t_{b}\right)\end{array}$ & $\begin{array}{l}\text { Profit }=\text { total revenue }- \text { cost } \\
\begin{aligned} \pi_{h} & =\left(F_{b} t_{b}+F_{c} t_{c}\right) \\
& -\left[C_{v h}\left(F_{b}+F_{c}\right)+C_{f h}\right]\end{aligned}\end{array}$ & $\begin{array}{l}F_{b}-\text { frequency of transit } \\
\text { service } \\
F_{c} \text {-private car demand }\end{array}$ & $\begin{array}{l}C_{v h}-\text { variable cost } \\
\text { proportional to total traffic } \\
\text { flow on highway } \\
C_{f h} \text {-fixed cost }\end{array}$ \\
\hline $\begin{array}{l}\text { Transit operator } \\
(b)\end{array}$ & $\begin{array}{l}\text { Maximise } \\
\text { profit }\end{array}$ & $\begin{array}{ll}\text { - } & \text { Frequency of } \\
\text { service }\left(F_{b}\right) & \\
\text { - } & \text { Fare }\left(f_{b}\right)\end{array}$ & $\begin{array}{l}\text { Profit }=\text { total revenue }- \text { operating } \\
\text { cost }- \text { toll cost } \\
\pi_{b}=f_{b} Q_{b}-\left(C_{v b} F_{b}+C_{f b}\right)-F_{b} t_{b}\end{array}$ & $\begin{array}{l}t_{b}-\text { toll for transit vehicle } \\
Q_{b} \text {-transit patronage }\end{array}$ & $\begin{array}{l}C_{v b}-\text { variable cost } \\
\text { proportional to fleet size } \\
C_{f b} \text {-fixed cost }\end{array}$ \\
\hline $\begin{array}{l}\text { Private vehicle } \\
(\mathrm{PV}) \text { users }(c)\end{array}$ & \multirow[t]{2}{*}{$\begin{array}{l}\text { Minimise } \\
\text { generalised } \\
\text { cost }\end{array}$} & \multirow{2}{*}{$\begin{array}{l}\text { - Whether to travel } \\
\text { by car /bus which } \\
\text { is determined } \\
\text { based on the VOT } \\
\text { of the users }(\tau)\end{array}$} & \multirow{2}{*}{$\begin{array}{l}\text { Generalised costs } \\
G_{b}(\tau)=f_{b}+\left(T_{b}+W\left(F_{b}\right)\right) \tau \\
G_{c}(\tau)=f_{c}+T_{c} \tau+t_{c} \\
G_{r}(\tau)=f_{r}+T_{r} \tau \\
\text { where } \\
W\left(F_{b}\right)=\frac{1}{2 F_{b}}\end{array}$} & \multirow{2}{*}{$\begin{array}{l}f_{b} \text {-fare for transit } \\
F_{b}-\text { frequency of transit } \\
\text { service } \\
t_{c} \text {-toll charge for private } \\
\text { vehicle }\end{array}$} & \multirow{2}{*}{$\begin{array}{l}T_{b} \text {-travel time on transit } \\
f_{c} \text {-fixed monetary cost of } \\
\mathrm{PV} \text { (excluding toll) } \\
T_{c} \text {-travel time on PV } \\
f_{r} \text {-fare on railway } \\
T_{r} \text {-travel time on railway } \\
C_{v r} \text {-variable cost } \\
\text { proportional to patronage } \\
C_{f r} \text {-fixed cost }\end{array}$} \\
\hline $\begin{array}{lr}\text { Existing } & \text { mode } \\
\text { users- } & \text { say } \\
\text { railway }(r) & \end{array}$ & & & & & \\
\hline
\end{tabular}


Table 2. Details of the hypothetical case in the numerical analysis

\begin{tabular}{|c|c|c|}
\hline Category & Parameter & Value \\
\hline \multirow[t]{3}{*}{ Travel time } & $\begin{array}{l}\text { Travel time on private } \\
\text { vehicle }\left(T_{c}\right)\end{array}$ & 10 minutess \\
\hline & Travel time on transit $\left(T_{b}\right)$ & 30 minutes \\
\hline & $\begin{array}{l}\text { Travel time on virtual } \\
\text { mode }\left(T_{r}\right)\end{array}$ & 60 minutes \\
\hline \multirow[t]{2}{*}{ Travel cost /fare } & $\begin{array}{llll}\text { Fixed cost on private } \\
\text { vehicle }\left(f_{c}\right)\end{array}$ & $\$ 50$ \\
\hline & Fare on virtual mode $\left(f_{r}\right)$ & $\$ 5$ \\
\hline \multirow[t]{2}{*}{ VOT distribution $f(\tau)$} & Upper bound of VOT $\left(\theta_{2}\right)$ & $\$ 139$ per hour \\
\hline & Lower bound of $\operatorname{VOT}\left(\theta_{1}\right)$ & $\$ 1$ per hour \\
\hline \multirow[t]{2}{*}{ Transit operating cost } & Fixed cost $\left(C_{f b}\right)$ & $\$ 100$ per hour \\
\hline & Variable cost $\left(C_{v b}\right)$ & $\$ 300$ per bus trip \\
\hline \multirow{2}{*}{$\begin{array}{l}\text { Virtual mode operating } \\
\text { cost }\end{array}$} & Fixed cost $\left(C_{f r}\right)$ & $\$ 100$ per hour \\
\hline & Variable cost $\left(C_{v r}\right)$ & $\$ 2$ per passenger trip \\
\hline \multirow[t]{2}{*}{ Highway operating cost } & Fixed cost $\left(C_{f h}\right)$ & $\$ 100$ per hour \\
\hline & Variable cost $\left(C_{v h}\right)$ & $\$ 10$ per vehicle trip \\
\hline Total demand & $Q$ & $\begin{array}{l}4000 \text { passenger trips per } \\
\text { hour }\end{array}$ \\
\hline Bus capacity & $H_{b}$ & 60 passengers per bus \\
\hline
\end{tabular}




\begin{tabular}{|c|c|c|c|c|c|c|c|c|}
\hline & \multirow{2}{*}{$\begin{array}{c}\text { No } \\
\text { transit } \\
\text { service }\end{array}$} & \multirow[t]{2}{*}{ Game A } & \multicolumn{2}{|c|}{ Game $\mathrm{B}^{1}$} & \multirow[t]{2}{*}{ Game C } & \multirow[t]{2}{*}{ Game $D^{1}$} & \multirow{2}{*}{$\begin{array}{c}\text { Monopoly } \\
\text { case }\end{array}$} & \multirow{2}{*}{$\begin{array}{c}\text { Social } \\
\text { optimal }\end{array}$} \\
\hline & & & Unconstrained & Constrained $^{2}$ & & & & \\
\hline Toll for private vehicles $(\$)$ & 40.5 & 40.0 & 7.0 & 12.5 & 40.9 & 18.6 & 40 & 2.1 \\
\hline Toll for transit vehicles $(\$)$ & - & 2,162 & 11 & 544 & 2,521 & 855 & - & \\
\hline Fare for transit $(\$)$ & - & 45.6 & 10.0 & 15.0 & 47.2 & 21.0 & 38.4 & 4.6 \\
\hline Frequency (per hour) & - & 17.8 & 119.9 & 61.0 & 11.3 & 56.0 & 34.0 & 64.6 \\
\hline Fare for rail $(\$)$ & 5.0 & 5.0 & 5.0 & 5.0 & 5.0 & 5.0 & 5.0 & 2.0 \\
\hline Spare capacity on transit (trips per hour) & 0 & 0 & 3,457 & 220 & 0 & 274 & 0 & 0 \\
\hline Profit for transit operator (\$ per hour) & - & 4,759 & 0 & 0 & 0 & 0 & \multirow[t]{2}{*}{67,491} & \multirow[t]{2}{*}{-2325} \\
\hline Profit for highway operator ( $\$$ per hour) & 32,210 & 52,362 & 2 & 32,496 & 49,054 & 47,244 & & \\
\hline Profit for rail operator (\$ per hour) & 8,722 & 7,280 & 779 & 1,669 & 7,847 & 2,732 & 5,781 & -99 \\
\hline Social cost ( $\$$ per hour) & 243,314 & 215,277 & 179,997 & 165,673 & 226,163 & 169,639 & 192,252 & 163,136 \\
\hline No. of private vehicle users (per hour) & 1,059 & 472 & 0 & 0 & 675 & 0 & 0 & 0 \\
\hline No. of transit service users (per hour) & 0 & 1,068 & 3,737 & 3,440 & 676 & 3,086 & 2,040 & 3,876 \\
\hline No. of rail users (per hour) & 2,941 & 2,460 & 263 & 560 & 2,649 & 914 & 1,960 & 124 \\
\hline
\end{tabular}

Note: 1.Based on the primary objective of profit maximisation, the resulting equilibria in Games B and D are non-unique. The equilibria illustrated are the solutions determined based on a secondary objective of the transit operator as patronage maximisation.

2.The constrained solution in Game B is constrained by highway operator's profits under prohibitive transit pricing. 


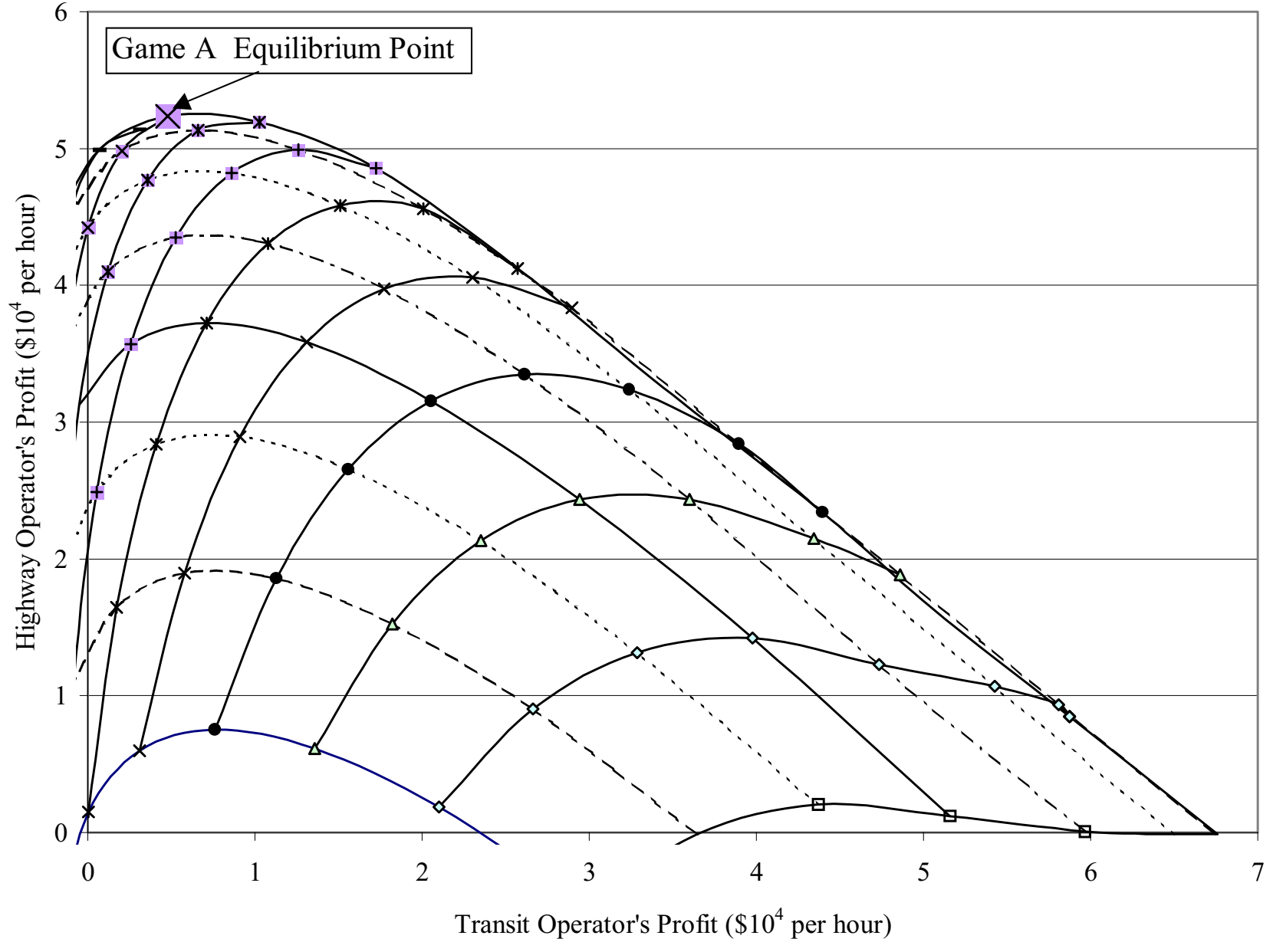

- Private toll $=\$ 5$

- - - Private toll $=\$ 10$

. . . . . Private toll $=\$ 15$

- Private toll $=\$ 20$

- - - Private toll $=\$ 25$

. . . . Private toll $=\$ 30$

- - - Private toll $=\$ 35$

— Private toll $=\$ 40$

$\square$ Tranist toll $=\$ 10$

$\leadsto$ Tranist toll $=\$ 279$

$\longrightarrow$ Tranist toll $=\$ 548$

$\longrightarrow$ Tranist toll $=\$ 817$

$\longrightarrow$ Tranist toll $=\$ 1086$

* Tranist toll $=\$ 1355$

$\longrightarrow$ Tranist toll $=\$ 1624$

——- Tranist toll $=\$ 1893$

$-x-$ Tranist toll $=\$ 2162$

— Tranist toll $=\$ 2431$ Tranist toll $=\$ 2700$

Figure 1. Profits distribution in Game A 


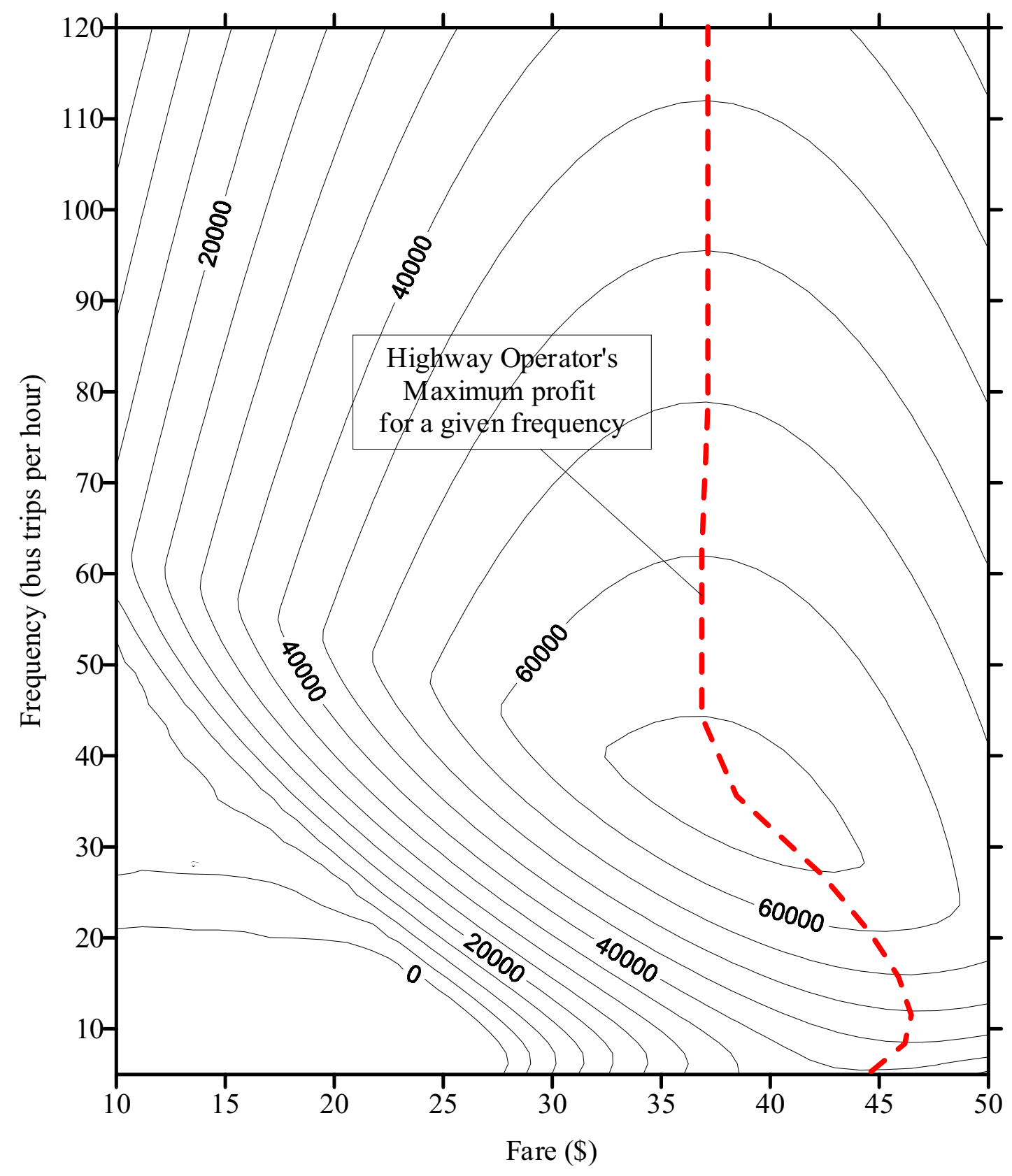

Figure 2. Highway operator's optimised profits in Game B 


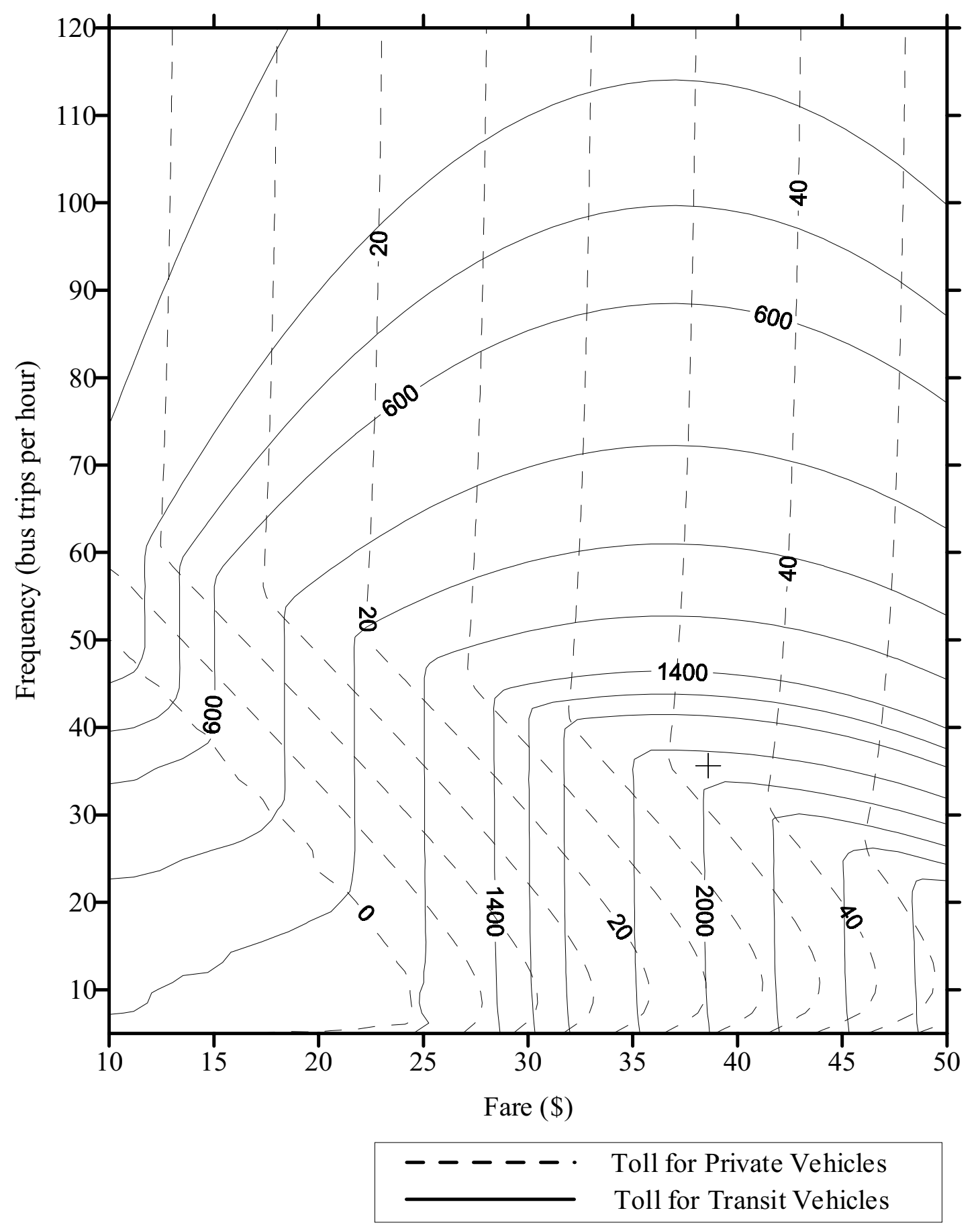

Figure 3. Highway operator's optimised tolls in Game B 


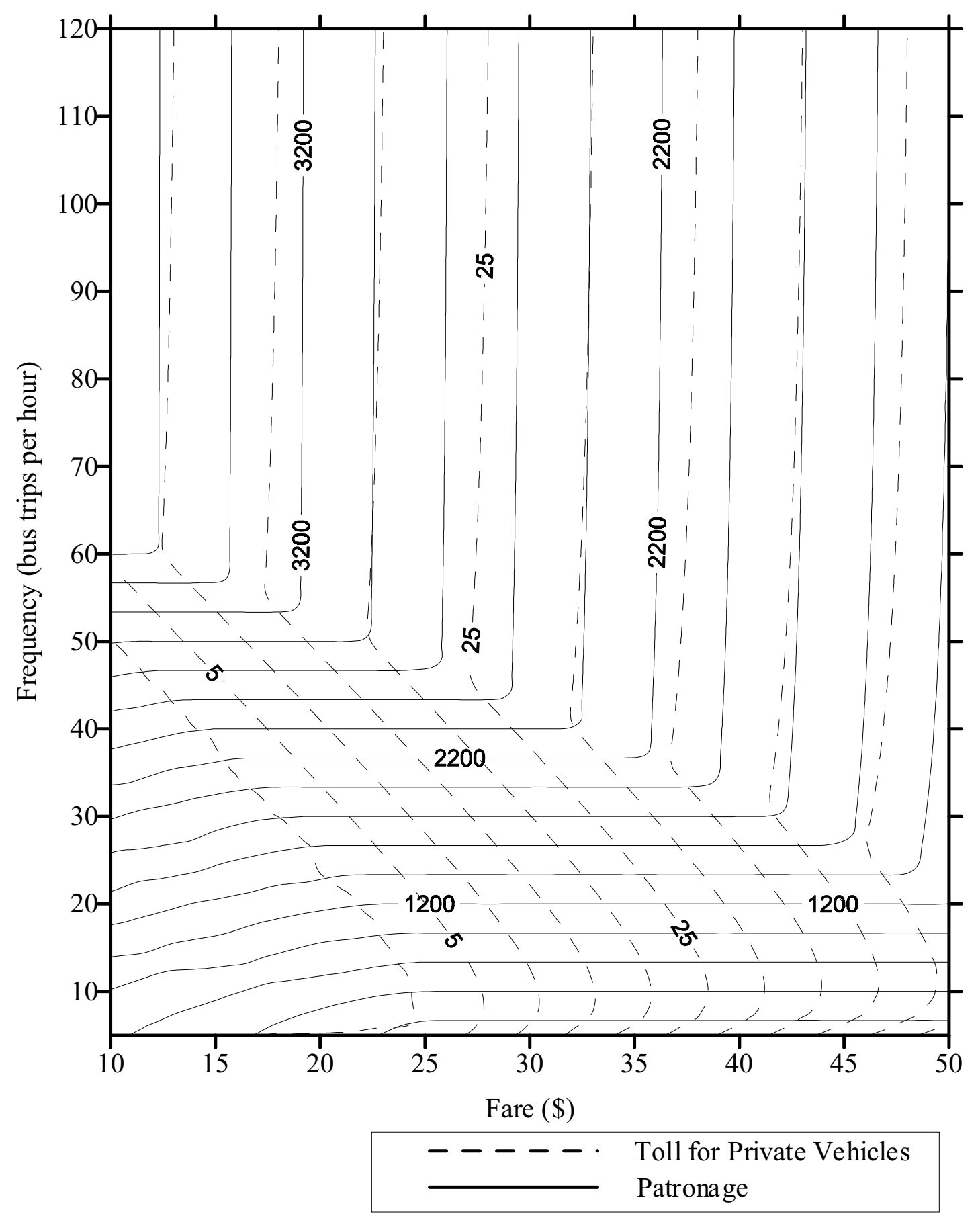

Figure 4. Transit operator's expected patronage in Game B 


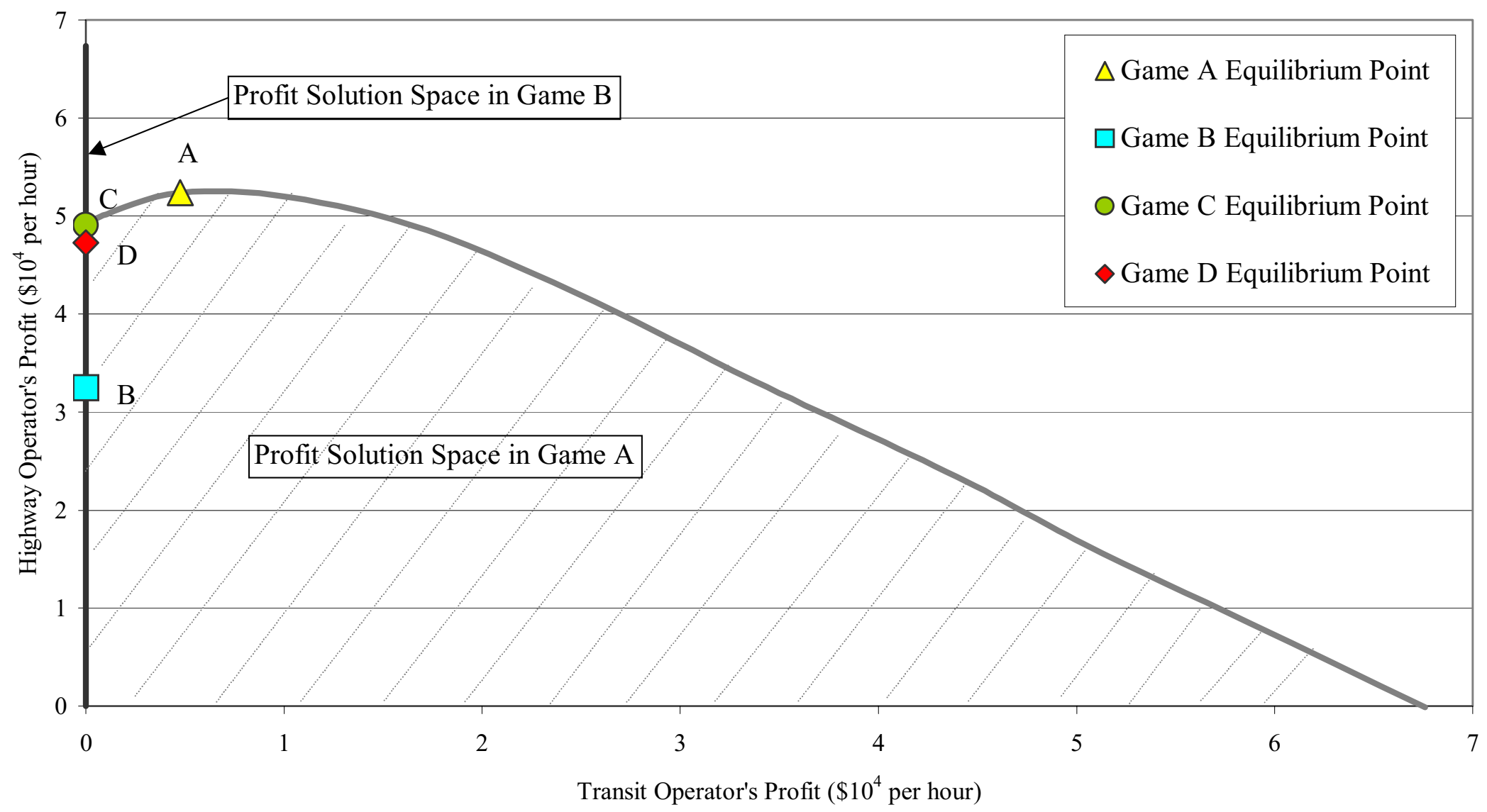

Figure 5. The highway and transit operators' profit at equilibrium of various games 
Wang Yang Verhoef: Strategic interactions on a private highway

Appendix A Derivation of the derivatives in the demand equilibrium model

$\bar{\tau}_{b c}=\left(f_{c}+t_{c}-f_{b}\right)\left(T_{b}+\frac{1}{2 F_{b}}-T_{c}\right)^{-1}$

$\frac{\partial \bar{\tau}_{b c}}{\partial f_{b}}=-\left(T_{b}+\frac{1}{2 F_{b}}-T_{c}\right)^{-1}$

$\frac{\partial \bar{b}_{b c}}{\partial F_{b}}=\left(\frac{f_{c}+t_{c}-f_{b}}{2 F_{b}^{2}}\right)\left(T_{b}+\frac{1}{2 F_{b}}-T_{c}\right)^{-2}$

$\frac{\partial \bar{t}_{b c}}{\partial t_{c}}=\left(T_{b}+\frac{1}{2 F_{b}}-T_{c}\right)^{-1}$

$\bar{\tau}_{b r}=\left(f_{b}-f_{r}\right)\left(T_{r}-T_{b}-\frac{1}{2 F_{b}}\right)^{-1}$

$\frac{\partial \bar{\tau}_{b r}}{\partial f_{b}}=\left(T_{r}-T_{b}-\frac{1}{2 F_{b}}\right)^{-1}$

$\frac{\partial \bar{b}_{b r}}{\partial F_{b}}=-\left(\frac{f_{b}-f_{r}}{2 F_{b}^{2}}\right)\left(T_{r}-T_{b}-\frac{1}{2 F_{b}}\right)^{-2}$

$Q_{b}=Q \int_{\bar{\tau}_{\bar{t}_{r}}}^{\bar{\tau}_{b_{c}}} f(x) d x=\left(\frac{\bar{\tau}_{b c}-\bar{\tau}_{b r}}{\theta_{2}-\theta_{1}}\right) Q$

$\frac{\partial Q_{b}}{\partial f_{b}}=\left(\frac{Q}{\theta_{2}-\theta_{1}}\right)\left(\frac{\partial \bar{t}_{b c}}{\partial f_{b}}-\frac{\partial \bar{\tau}_{b r}}{\partial f_{b}}\right)$

$\frac{\partial Q_{b}}{\partial F_{b}}=\left(\frac{Q}{\theta_{2}-\theta_{1}}\right)\left(\frac{\partial \bar{\tau}_{b c}}{\partial F_{b}}-\frac{\partial \bar{\tau}_{b r}}{\partial F_{b}}\right)$ 
Appendix B Derivation of optimal toll charges in Game B

If the transit operator can only breakeven, i.e. making zero profit

$\pi_{b}\left(f_{b}, F_{b}\right)=f_{b} Q_{b}\left(f_{b}, F_{b}, t_{c}\right)-C_{v b} F_{b}-C_{f b}-F_{b} t_{b}=0$

Solving for $t_{b}$ from eqn. (B1) gives

$t_{b}^{*}=\frac{f_{b} Q_{b}\left(f_{b}, F_{b}, t_{c}\right)-C_{v b} F_{b}-C_{f b}}{F_{b}}$

To determine the optimal private vehicle toll, the first order condition is,

$$
\begin{aligned}
& \frac{\partial \pi_{h}}{\partial t_{c}}=f_{b} \frac{\partial Q_{b}}{\partial t_{c}}+F_{c}+\left(t_{c}-C_{v h}\right) \frac{\partial F_{c}}{\partial t_{c}}=0 \\
& f_{b}\left(\frac{Q}{\theta_{2}-\theta_{1}}\right) \frac{\partial \bar{\tau}_{b c}}{\partial t_{c}}+Q\left(\frac{\theta_{2}-\bar{\tau}_{b c}}{\theta_{2}-\theta_{1}}\right)+\left(t_{c}-C_{v h}\right)\left(\frac{-Q}{\theta_{2}-\theta_{1}}\right) \frac{\partial \bar{\tau}_{b c}}{\partial t_{c}}=0
\end{aligned}
$$

Substitute eqns. (A1) and (A4) into eqn. (B4) and rearranging gives,

$$
t_{c}^{*}=\frac{1}{2}\left[\theta_{2}\left(T_{b}+\frac{1}{2 F_{b}}-T_{c}\right)-f_{c}+2 f_{b}+C_{v h}\right]
$$

The capacity constraint of the transit operator is

$$
F_{b} H_{b}-Q_{b}\left(f_{b}, F_{b}, t_{c}\right) \geq 0
$$

Substituting the demand equilibrium conditions into the constraint gives

$$
\begin{aligned}
& F_{b} H_{b}-\left(\frac{\bar{\tau}_{b c}-\bar{\tau}_{b r}}{\theta_{2}-\theta_{1}}\right) Q \geq 0 \\
& F_{b} H_{b}-\left(\frac{Q}{\theta_{2}-\theta_{1}}\right)\left[\left(f_{c}+t_{c}-f_{b}\right)\left(T_{b}+\frac{1}{2 F_{b}}-T_{c}\right)^{-1}-\left(f_{b}-f_{r}\right)\left(T_{r}-T_{b}-\frac{1}{2 F_{b}}\right)^{-1}\right] \geq 0 \\
& t_{c} \leq\left[T_{b}+\frac{1}{2 F_{b}}-T_{c}\right] \\
& {\left[F_{b} H_{b}\left(\frac{Q}{\theta_{2}-\theta_{1}}\right)^{-1}+\left(f_{b}-f_{r}\right)\left(T_{r}-T_{b}-\frac{1}{2 F_{b}}\right)^{-1}-\left(f_{c}-f_{b}\right)\left(T_{b}+\frac{1}{2 F_{b}}-T_{c}\right)^{-1}\right]}
\end{aligned}
$$


Wang Yang Verhoef: Strategic interactions on a private highway

$$
\begin{aligned}
t_{c}^{U B} & =\left[T_{b}+\frac{1}{2 F_{b}}-T_{c}\right] \\
& {\left[F_{b} H_{b}\left(\frac{Q}{\theta_{2}-\theta_{1}}\right)^{-1}+\left(f_{b}-f_{r}\right)\left(T_{r}-T_{b}-\frac{1}{2 F_{b}}\right)^{-1}-\left(f_{c}-f_{b}\right)\left(T_{b}+\frac{1}{2 F_{b}}-T_{c}\right)^{-1}\right] }
\end{aligned}
$$

For the boundary case of private vehicles being unattractive to any users,

$$
\begin{aligned}
& \bar{\tau}_{b c}=\left(f_{c}+t_{c}^{\max }-f_{b}\right)\left(T_{b}+\frac{1}{2 F_{b}}-T_{c}\right)^{-1}=\theta_{2} \\
& t_{c}^{\max }=\left(T_{b}+\frac{1}{2 F_{b}}-T_{c}\right) \theta_{2}+f_{b}-f_{c}
\end{aligned}
$$


Appendix C Derivation of optimal transit fares in Game D

The optimal condition for the Lagrangian formulation is

$$
\begin{aligned}
& \frac{\partial \ell \pi_{b}}{\partial f_{b}}=0 \\
& \bar{F}_{b} H_{b}-Q_{b}\left(f_{b}, \bar{F}_{b}, t_{c}\right) \geq 0 \\
& \lambda_{b}\left(\bar{F}_{b} H_{b}-Q_{b}\left(f_{b}, \bar{F}_{b}, t_{c}\right)\right)=0 \\
& \lambda_{b} \geq 0
\end{aligned}
$$

Elaborating eqn. (C1):

$$
\begin{aligned}
& \frac{\partial \ell \pi_{b}}{\partial f_{b}}=\left(\lambda_{b}-f_{b}\right) \frac{\partial Q_{b}}{\partial f_{b}}-Q_{b}=0 \\
& \frac{\partial \ell \pi_{b}}{\partial f_{b}}=\left(\lambda_{b}-f_{b}\right)\left(\frac{Q}{\theta_{2}-\theta_{1}}\right)\left(\frac{\partial \bar{\tau}_{b c}}{\partial f_{b}}-\frac{\partial \bar{\tau}_{b r}}{\partial f_{b}}\right)-\left(\frac{\bar{\tau}_{b c}-\bar{\tau}_{b r}}{\theta_{2}-\theta_{1}}\right) Q=0
\end{aligned}
$$

The expressions of the derivatives as illustrated in Appendix A are substituted into eqn. (C6).

The solution to the above formulation will depend on whether the demand flow of private vehicles is greater than zero and whether the capacity constraint is binding condition.

To solve this equation, we have four possible cases:

- $\quad$ Case $1-\lambda_{b}=0$, PV Demand $F_{c}>0$

Substitute $\lambda_{b}=0$ into eqn. (C6) and solve for $f_{b}$, we have

$$
f_{b}^{*}=\frac{\left(f_{c}+t_{c}\right)\left(T_{b}+\frac{1}{2 \bar{F}_{b}}-T_{c}\right)^{-1}+f_{r}\left(T_{r}-T_{b}-\frac{1}{2 \bar{F}_{b}}\right)^{-1}}{2\left[\left(T_{b}+\frac{1}{2 \bar{F}_{b}}-T_{c}\right)^{-1}+\left(T_{r}-T_{b}-\frac{1}{2 \bar{F}_{b}}\right)^{-1}\right]}
$$

- $\quad$ Case $2-\lambda_{b}=0$, PV Demand $F_{c}=0$ 
Substitute $\lambda_{b}=0$ into eqn. (C6) and since $F_{c}=0, \frac{\partial \bar{\tau}_{b c}}{\partial f_{b}}=0$ and $\bar{\tau}_{b c}=\theta_{2}$, solve for $f_{b}$, we have

$$
f_{b}^{*}=\frac{1}{2}\left(T_{r}-T_{b}-\frac{1}{2 \bar{F}_{b}}\right)\left[\theta_{2}+f_{r}\left(T_{r}-T_{b}-\frac{1}{2 \bar{F}_{b}}\right)^{-1}\right]
$$

- $\quad$ Case $3-\lambda_{b}>0$, PV Demand $F_{c}>0$

When $\lambda_{b}>0$, the capacity constraint becomes binding,

$$
\begin{aligned}
& \bar{F}_{b} H_{b}-Q_{b}\left(f_{b}, \bar{F}_{b}, t_{c}\right)=0 \\
& \bar{F}_{b} H_{b}-\left(\frac{\bar{\tau}_{b c}-\bar{\tau}_{b r}}{\theta_{2}-\theta_{1}}\right) Q=0
\end{aligned}
$$

Solve for $f_{b}$ in eqn. (C10), we have

$$
f_{b}^{*}=\frac{\left(f_{c}+t_{c}\right)\left(T_{b}+\frac{1}{2 \bar{F}_{b}}-T_{c}\right)^{-1}+f_{r}\left(T_{r}-T_{b}-\frac{1}{2 \bar{F}_{b}}\right)^{-1}-\bar{F}_{b} H_{b}\left(\frac{Q}{\theta_{2}-\theta_{1}}\right)^{-1}}{\left(T_{r}-T_{b}-\frac{1}{2 \bar{F}_{b}}\right)^{-1}+\left(T_{b}+\frac{1}{2 \bar{F}_{b}}-T_{c}\right)^{-1}}
$$

- $\quad$ Case $4-\lambda_{b}>0$, PV Demand $F_{c}=0$

Since $F_{c}=0, \bar{\tau}_{b c}=\theta_{2}$, solve for $f_{b}$ in eqn. (C10), we have

$$
f_{b}^{*}=\left(T_{r}-T_{b}-\frac{1}{2 \bar{F}_{b}}\right)\left[\theta_{2}+f_{r}\left(T_{r}-T_{b}-\frac{1}{2 \bar{F}_{b}}\right)^{-1}-\bar{F}_{b} H_{b}\left(\frac{Q}{\theta_{2}-\theta_{1}}\right)^{-1}\right]
$$


Appendix D Derivation of derivatives for the monopoly case - only one service provider providing the highway and transit service

$$
\begin{gathered}
\frac{\partial F_{c}}{\partial f_{b}}=-\left(\frac{Q}{\theta_{2}-\theta_{1}}\right) \frac{\partial \bar{\tau}_{b c}}{\partial f_{b}} \\
\frac{\partial F_{c}}{\partial F_{b}}=-\left(\frac{Q}{\theta_{2}-\theta_{1}}\right) \frac{\partial \bar{\tau}_{b c}}{\partial F_{b}} \\
\frac{\partial F_{c}}{\partial t_{c}}=-\left(\frac{Q}{\theta_{2}-\theta_{1}}\right) \frac{\partial \bar{\tau}_{b c}}{\partial t_{c}}
\end{gathered}
$$

$$
\frac{\partial Q_{b}}{\partial f_{b}}=\left(\frac{Q}{\theta_{2}-\theta_{1}}\right)\left(\frac{\partial \bar{\tau}_{b c}}{\partial f_{b}}-\frac{\partial \bar{\tau}_{b r}}{\partial f_{b}}\right)
$$

$$
\frac{\partial Q_{b}}{\partial F_{b}}=\left(\frac{Q}{\theta_{2}-\theta_{1}}\right)\left(\frac{\partial \bar{\tau}_{b c}}{\partial F_{b}}-\frac{\partial \bar{\tau}_{b r}}{\partial F_{b}}\right)
$$

$\frac{\partial Q_{b}}{\partial t_{c}}=\left(\frac{Q}{\theta_{2}-\theta_{1}}\right) \frac{\partial \bar{\tau}_{b c}}{\partial t_{c}}$

$$
\bar{\tau}_{b c}=\left(f_{c}+t_{c}-f_{b}\right)\left(T_{b}+\frac{1}{2 F_{b}}-T_{c}\right)^{-1}
$$

$$
\frac{\partial \bar{\tau}_{b c}}{\partial f_{b}}=-\left(T_{b}+\frac{1}{2 F_{b}}-T_{c}\right)^{-1}
$$

$\frac{\partial \bar{\tau}_{b c}}{\partial F_{b}}=\left(\frac{f_{c}+t_{c}-f_{b}}{2 F_{b}^{2}}\right)\left(T_{b}+\frac{1}{2 F_{b}}-T_{c}\right)^{-2}$

$\frac{\partial \bar{\tau}_{b c}}{\partial t_{c}}=\left(T_{b}+\frac{1}{2 F_{b}}-T_{c}\right)^{-1}$

$$
\bar{\tau}_{b r}=\left(f_{b}-f_{r}\right)\left(T_{r}-T_{b}-\frac{1}{2 F_{b}}\right)^{-1}
$$


Wang Yang Verhoef: Strategic interactions on a private highway

$$
\begin{aligned}
& \frac{\partial \bar{\tau}_{b r}}{\partial f_{b}}=\left(T_{r}-T_{b}-\frac{1}{2 F_{b}}\right)^{-1} \\
& \frac{\partial \bar{\tau}_{b r}}{\partial F_{b}}=-\left(\frac{f_{b}-f_{r}}{2 F_{b}^{2}}\right)\left(T_{r}-T_{b}-\frac{1}{2 F_{b}}\right)^{-2} \\
& \frac{\partial \bar{\tau}_{b r}}{\partial t_{c}}=0
\end{aligned}
$$

